\title{
Changements d'occupation et d'usage des terres entre 2016 et 2019 dans le Sud-Est de la Côte d'Ivoire : impact des cultures de rente sur la forêt
}

\author{
Tiodionwa Abdoulaye OUATTARA ${ }^{1,5}$ \\ Koffi Fernand KouAmÉ ${ }^{1,2}$ \\ Irié Casimir Zo-BI ${ }^{3}$ \\ Romuald VAUDRY ${ }^{4}$ \\ Clovis GRINAND ${ }^{4}$
}

${ }^{1}$ Centre universitaire de recherche et d'application en télédétection (CURAT) 22 BP 801, Abidjan 22

Côte d'Ivoire

${ }^{2}$ Université virtuelle de Côte d'Ivoire (UVCI) 28 BP 536, Abidjan 28

Côte d'Ivoire

${ }^{3}$ Institut national polytechnique Félix Houphouët-Boigny (INP-HB) BP 1313, Yamoussoukro

Côte d'Ivoire

\section{${ }^{4}$ NITIDÆE}

29 rue Imbert-Colomés

69001 Lyon

France

\section{${ }^{5}$ NITID}

Tour Wedge (8e étage)

Les Caddies, Riviera Golf

Cocody

25 BP 691, Abidjan 25

Côte d'Ivoire

Auteur correspondant / Corresponding author: Tiodionwa Abdoulaye OUATTARA otiodionwabdoulaye@vahoo.fr

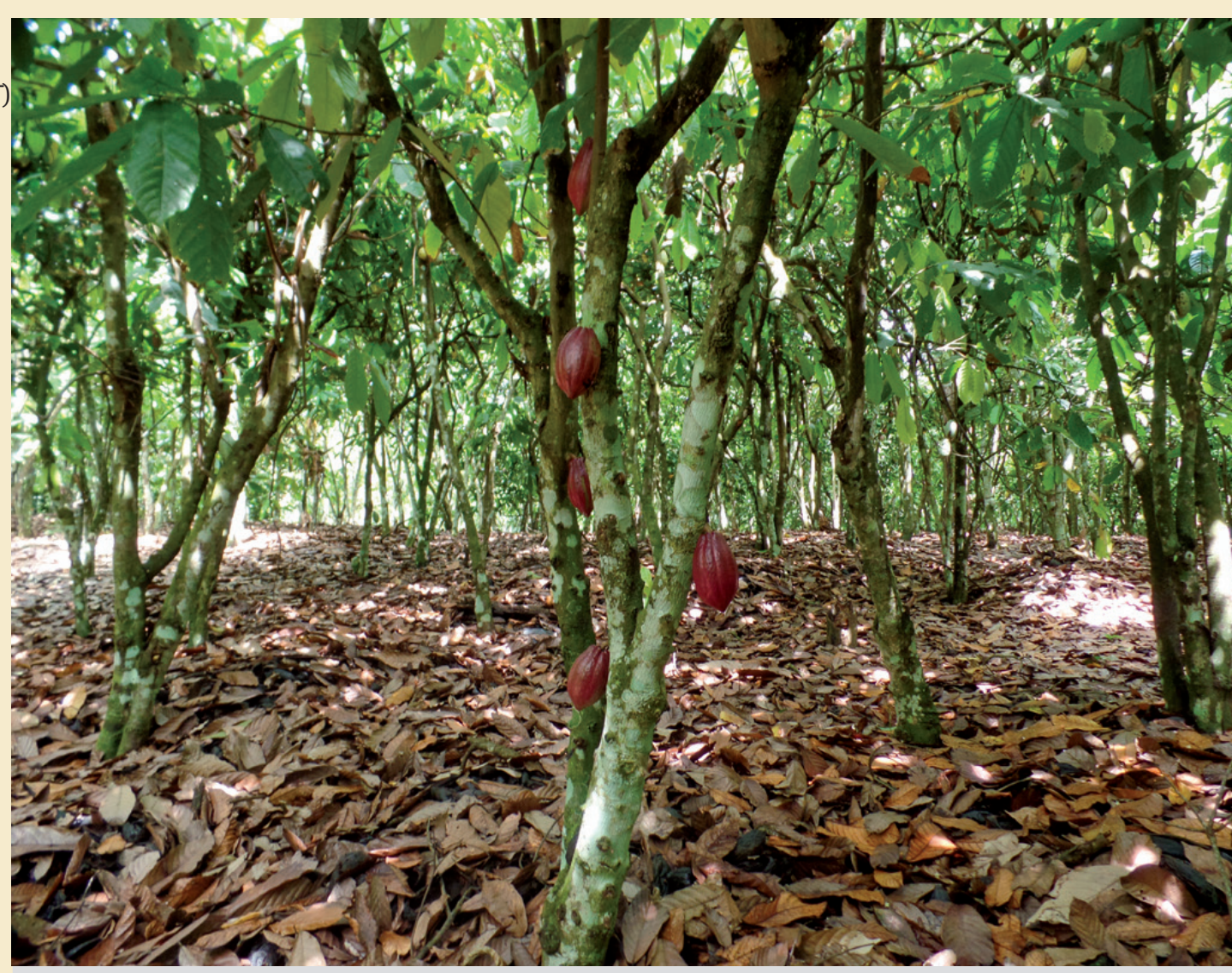

Photo 1.

Cacaoyère «plein soleil » en production (principale culture de la Côte d'Ivoire). A "full sun" cocoa plantation in production (main crop in Ivory Coast). Photo T. A. Ouattara.

Doi : 10.19182/bft2021.347.a31868 - Droit d'auteur (c) 2021, Bois et Forêts des Tropiques - (c) Cirad - Date de soumission : 16 juin 2020 ; date d'acceptation : 16 décembre 2020 ; date de publication : 25 février 2021.

\section{Ccirad at}

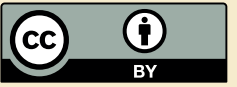

Citer l'article / To cite the article

Ouattara T. A., Kouamé K. F., Zo-Bi I. C., Vaudry R., Grinand C., 2021. Changements d'occupation et d'usage des terres entre 2016 et 2019 dans le Sud-Est de la Côte d'Ivoire : impact des cultures de rente sur la forêt. Bois et Forêts des Tropiques, 347: 89-104. Doi : https://doi.org/10.19182/ bft2021.347.a31868 


\section{RÉSUMÉ}

\section{Changements d'occupation et d'usage des terres entre 2016 et 2019 dans le Sud-Est de la Côte d'Ivoire : impact des cultures de rente sur la forêt}

En Côte d'Ivoire, plus de la moitié du couvert forestier ( $57 \%$ ) a disparu en un quart de siècle (1990-2015) avec une perte importante de biodiversité. Pour mieux comprendre les dynamiques en cours et appuyer les politiques de réduction de la déforestation, des cartographies fines et régulières des changements d'occupation et d'usage des terres sont nécessaires. Cependant, ces études sont rarement conduites sur de grands territoires ou bien elles sont parfois obsolètes à cause de la rapidité des processus anthropiques sous-jacents. L'objectif de cette étude est d'évaluer les changements d'occupation et d'usage des terres, en particulier les dynamiques de déforestation et de dégradation forestière dans trois régions du Sud-Est de la Côte d'Ivoire, entre 2016 et 2019. La méthodologie est basée sur l'utilisation d'images Sentinel-2 à 10 et $20 \mathrm{~m}$ de résolution spatiale sur une zone d'étude de $22014 \mathrm{~km}^{2}$. Des données d'apprentissage ont d'abord été délimitées en suivant une description de la zone en 16 catégories d'occupation et d'usage des terres. Celles-ci ont ensuite été utilisées avec l'algorithme Random Forests pour produire des cartes d'occupation et d'usage des terres en 2016 et 2019 avec une précision globale respective de $92 \%$ et $87 \%$. Enfin, ces cartes ont été croisées pour décrire les transitions forestières de la zone étudiée. Les résultats révèlent que l'extension des cultures de rente (cacao-café, hévéa et palmier à huile), des cultures et jachères non différenciées ainsi que des infrastructures (habitations et routes) a conduit à un taux de déforestation de 4,95\% par an sur la période étudiée. Cette étude fournit ainsi une compréhension détaillée et actualisée des changements d'occupation et d'usage des terres, et contribue aux réflexions sur la mise en place d'un système national de surveillance des terres.

Mots-clés : occupation et usage des terres, Sentinel-2, déforestation, dégradation des forêts, cacaoculture, Random Forests, télédétection, Côte d'Ivoire.

\section{ABSTRACT}

\section{Changes in land cover and land use from 2016 to 2019 in south-east Côte d'Ivoire: impacts of cash crops on forests}

In Côte d'Ivoire, over half of all forest cover $(57 \%)$ has been destroyed in a quarter of a century (1990-2015), with considerable loss of biodiversity. In order to support policies aiming to reduce forest losses and to better understand the dynamics at work, detailed and regular mapping of land cover and land use changes is essential. However, mapping studies are rarely conducted over large areas and can quickly become obsolete because of the rapidly evolving human processes underlying changes. This study aims to assess changes in land cover and land use from 2016 to 2019 in three regions of south-eastern Côte d'Ivoire, with a particular focus on the dynamics of deforestation and forest degradation. The methodology is based on the use of images from Sentinel-2 with 10 to 20 -metre resolution over a study area covering $22,014 \mathrm{~km}^{2}$. Data for training purposes were first marked out according to a description of the zone identifying 16 land cover and land use categories. These were then analysed with the Random Forests algorithm to produce maps of land use and land cover in 2016 and 2019 with an overall precision of $92 \%$ and $87 \%$ respectively. Finally, the maps were cross-analysed to describe forest transitions in the study zone. The results clearly show that the extension of cash crops (cacao and coffee, rubber and oil palm), undifferentiated crops, fallow lands and infrastructure (dwellings and roads) has caused deforestation at a rate of $4.95 \%$ per year over the period investigated. Our study thus provides a detailed and up-to-date picture of changes in land cover and land use and input for discussions on the introduction of a national land use surveillance system.

Keywords: land cover and land use, Sentinel-2, deforestation, forest degradation, cacao crops, Random Forests, remote sensing, Côte d'Ivoire.
T. A. OUattara, K. F. Kouamé, I. C. Zo-Bı, R. VAUdRY, C. GRINAND

\section{RESUMEN}

\section{Cambios en la ocupación y el uso del suelo entre 2016 y 2019 en el sudeste de Costa de Marfil: impacto de los cultivos comerciales en el bosque}

En Costa de Marfil, más de la mitad de la cubierta forestal (el 57 \%) ha desaparecido en un cuarto de siglo (1990-2015) con una importante pérdida de biodiversidad. Para apoyar las políticas de reducción de la deforestación y comprender mejor la dinámica actual, es necesario realizar una cartografía fina y constante de los cambios en la ocupación y el uso del suelo. Sin embargo, estos estudios rara vez se llevan a cabo en grandes territorios o a veces son obsoletos debido a la velocidad de los procesos antrópicos subyacentes. El objetivo de este estudio es evaluar los cambios en la ocupación y el uso del suelo, en particular las dinámicas de deforestación y degradación forestal en tres regiones del sudeste de Costa de Marfil, entre 2016 y 2019. La metodología se basa en el uso de imágenes del satélite Sentinel-2 con una resolución espacial de 10 y 20 metros en un área de estudio de $22014 \mathrm{~km}^{2}$. Primero se delimitaron datos de aprendizaje según una descripción de la zona con 16 categorías de uso y ocupación del suelo. A continuación, las imágenes se trataron con el algoritmo Random Forests para producir mapas de uso y ocupación del suelo en 2016 y 2019 con una precisión global del 92 \% y del 87 \% respectivamente. Por último, estos mapas se cruzaron para describir las transiciones forestales en la zona de estudio. Los resultados señalan que la extensión de los cultivos comerciales (cacao-café, árbol de caucho y palma aceitera), los cultivos y el barbecho no diferenciados, así como las infraestructuras (viviendas y carreteras), provocaron una tasa de deforestación del 4,95 \% anual durante el periodo estudiado. Por lo tanto, este estudio proporciona un conocimiento detallado y actualizado de los cambios en el uso y la ocupación del suelo, e invita a reflexionar sobre el establecimiento de un sistema nacional de vigilancia del suelo.

Palabras clave: uso y ocupación del suelo, Sentinel-2, deforestación, degradación forestal, producción de cacao, Random Forests, teledetección, Costa de Marfil. 
Depuis la seconde moitié du XXe siècle, la déforestation en milieu tropical est au centre des débats internationaux (Brou et al., 2005 ; Nakouma et al., 2013). En Afrique de l'Ouest, les conversions des surfaces forestières en terres agricoles sur la période allant de 2000 à 2010 ont été estimées par la FAO à $19 \%$, ce qui correspond à une perte de surfaces forestières d'environ 870000 ha/an (FAO, 2010). Selon le Bureau national d'études techniques et de développement (BNETD) et le Secrétariat exécutif permanent de la REDD+ (SEP-REDD+), 57 \% des forêts de Côte d'Ivoire ont disparu entre 1990 et 2015, la couverture forestière étant passée de 7,8 millions d'hectares en 1990 à 5,1 millions d'hectares en 2000, puis à 3,4 millions d'hectares en 2015, soit environ $11 \%$ du territoire national (BNETD, 2016 ; FAO, SEP-REDD+, 2017). Les rares forêts rémanentes se trouvent dans le Sud-Ouest du pays, notamment dans le Parc national de Taï (réserve de biosphère et patrimoine mondial de l'UNESCO) et dans la forêt classée du Cavally ainsi que dans le Sud-Est du pays. Malheureusement, ces dernières forêts font de plus en plus l'objet de fortes pressions anthropiques qu'il convient d'endiguer rapidement (Oszwald et al., 2007). En effet, depuis les années 2000, alors que la déforestation régresse globalement sur l'ensemble du territoire national, elle continue de s'accroître dans les forêts classées avec un taux annuel de déforestation passant de 2,9\% entre 1990 et 2000 à 4,2 \% entre 2000 et 2015 (BNETD, 2016).

Face à cette situation, l'État Ivoirien a élaboré une nouvelle stratégie de préservation, de réhabilitation et d'extension de ses forêts et en a profité pour se doter d'un nouveau Code forestier en juillet 2019 (Ministère des Eaux et Forêts, 2019). La mise en œuvre de cette stratégie nécessite, entre autres, le suivi régulier de la dynamique d'occupation et d'usage des terres (Jofack Sokeng et al., 2019). Ces nouvelles connaissances constituent en effet une donnée essentielle pour de nombreuses applications scientifiques et opérationnelles, favorisée par l'avènement de nouveaux capteurs et de nouvelles méthodes d'analyse spatiale (Longaretti et al., 2016 ; Thiérion et al., 2017).

En Côte d'Ivoire, le suivi de la dynamique d'occupation et d'usage des terres par télédétection fait face à de nombreux défis. Les défrichements commencent de manière très discrète sur de petites surfaces pour s'étendre progressivement à l'ensemble de la forêt classée ou de l'aire protégée (Nakouma et al., 2013 ; Barima et al., 2016). Dans ce contexte, le recours classique aux images satellitaires de type Landsat (Dibi N'Da et al., 2008 ; Barima et al., 2009) est justifié par la forte disponibilité des archives d'images (sur plus de trente ans) mais peut être limité pour des suivis annuels à cause de leur faible fréquence d'acquisition et résolution spatiale $(30 \mathrm{~m})$. La constellation de satellites Sentinel-2 en opération depuis 2015 (Sentinel-2A) et 2017 (Sentinel-2B) fournit gratuitement des images à 10, 20 et 60 $\mathrm{m}$ de résolution. Cela représente un fort intérêt pour les institutions du Sud qui ne disposent pas toujours de moyens financiers suffisants à l'acquisition d'images payantes.
L'utilisation de ces capteurs permet d'envisager une plus forte discrimination des modes d'occupation et d'usage des terres et une disponibilité d'images sans nuage. En effet, la zone intertropicale, et en particulier la Côte d'Ivoire, est sujette à de fortes couvertures nuageuses qui limitent l'application de la télédétection optique (Jofack Sokeng et al., 2019). À l'instar de Phiri et al. (2020), plusieurs travaux montrent le potentiel des capteurs Sentinel-2 pour contribuer de manière significative à la surveillance terrestre. En Amazonie, des performances supérieures des images Sentinel-2 comparées aux images Landsat- 8 ont été enregistrées dans le cadre du suivi de l'exploitation forestière (Lima et al., 2019). En Côte d'Ivoire, ces images ont été utilisées par le BNETD pour cartographier l'occupation du sol en 2016 dans le cadre du projet de Surveillance spatiale des terres (SST) (BNETD, 2019). Cependant, il n'existe pas d'évaluation des changements d'occupation du sol permettant de documenter les dynamiques des paysages, notamment les usages des terres post-déforestation. La seule étude disponible qui s'apparente au sujet traité (BNETD, 2016) s'intéresse uniquement aux pertes de couvert forestier dense humide, à l'aide de données Landsat et l'algorithme Maximum de vraisemblance, sans traiter des modes d'usage des terres post-déforestation. Comme indiqué plus haut, en Côte d'Ivoire, les conversions des forêts sont très rapides, il semble urgent d'explorer de nouvelles techniques de cartographie (données, outils et méthodes) permettant de cartographier les usages des terres annuellement ou à intervalle de temps réduit.

Les techniques de traitement d'images satellitaires ont beaucoup évolué ces dernières années avec l'usage des données Sentinel-2 et celui de plus en plus fréquent d'algorithmes de fouille de données, à l'instar de l'algorithme Random Forests (Breiman, 2001 ; Gislason et al., 2006). Cet algorithme a gagné en popularité dans le domaine de la télédétection et a été utilisé pour la cartographie de nombreux indicateurs environnementaux, par exemple la biomasse (Mutanga et al., 2012), le couvert forestier (Niculescu et al., 2018), l'indice LAI (Vuolo et Atzberger, 2014) et l'azote du couvert végétal (Li et al., 2014). Ces études démontrent la supériorité de la qualité des résultats obtenus par cette méthode par rapport aux méthodes conventionnelles, paramétriques et non paramétriques (Verrelst et al., 2015).

La présente étude vise à évaluer les changements d'occupation et d'usage des terres, en particulier les dynamiques de déforestation et de dégradation forestière dans trois régions du Sud-Est de la Côte d'Ivoire, entre 2016 et 2019. La méthodologie développée s’appuie sur les images satellites Sentinel-2, l'algorithme Random Forests et un effort de collecte de données d'apprentissage en 16 catégories d'usage des terres. La finalité de ces travaux est d'apporter de nouvelles connaissances afin de contribuer à la gestion durable des terres et à la lutte contre les défrichements illégaux dans les forêts classées et les aires protégées de la Côte d'Ivoire. 


\section{Matériel et méthodes}

\section{Zone d'étude}

La zone d'étude est située dans le Sud-Est de la Côte d'Ivoire. Elle couvre une superficie de $22014 \mathrm{~km}^{2}$ comprise entre $05^{\circ} 06^{\prime} 00^{\prime \prime}$ et $07^{\circ} 21^{\prime} 00^{\prime \prime}$ de latitude Nord et entre $02^{\circ} 43^{\prime} 00^{\prime \prime}$ et $04^{\circ} 11^{\prime} 00^{\prime \prime}$ de longitude Ouest (figure 1). Elle se subdivise en trois régions : la région de la Mé dont le chef-lieu est Adzopé, la région du Sud-Comoé (Aboisso) et la région de l'Indénié-Djuablin (Abengourou).

Le choix de cette zone d'étude s'explique par sa grande diversité des catégories d'occupation et d'usage des terres (Brou et al., 2005). En effet, ses paysages sont marqués par une importante mosaïque liée à son histoire agraire et à une forte proportion de forêts secondaires principalement issues des vieilles plantations de cacaoyers, Theobroma cacao (Sterculiaceae), et de caféiers, Coffea arabusca et Coffea canephora (Rubiaceae), abandonnées par leurs propriétaires. La photo 1 présente une cacaoyère « plein soleil » en production (principale culture de rente de la Côte d'Ivoire).

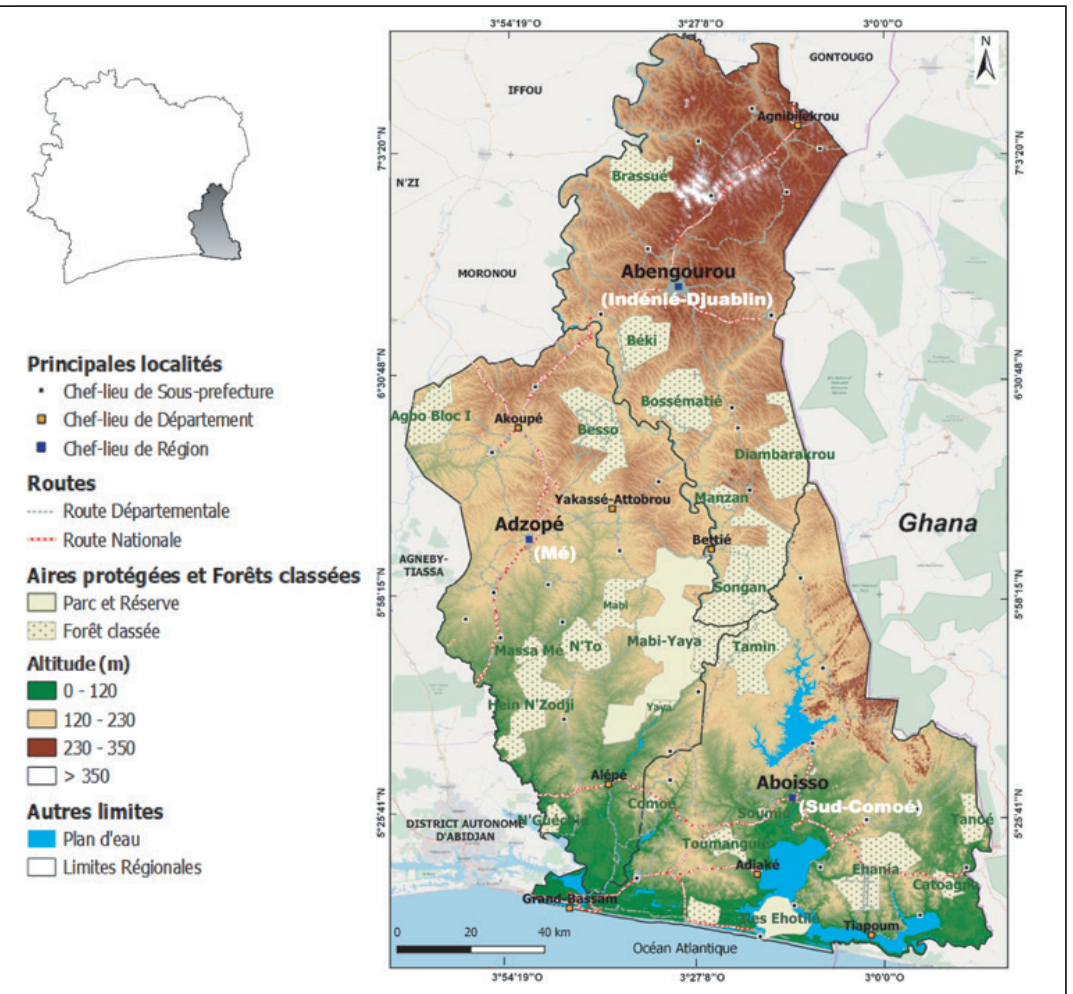

Figure 1.

Situation géographique de la zone d'étude et de trois régions du Sud-Est de la Côte d'Ivoire (Mé, Sud-Comoé et IndéniéDjuablin) ainsi qu'un aperçu du relief, des forêts classées et des aires protégées.

Geographical location of the study area and three regions of South-East Côte d'Ivoire (Mé, Sud-Comoé and IndéniéDjuablin) as well as an overview of the relief, classified forests and protected areas.
Cette zone d'étude abrite par ailleurs 23 forêts classées et deux aires protégées dont la réserve naturelle MabiYaya et le parc national des îles Ehotilé qui est classé site Ramsar. Ces forêts sont menacées de disparition du fait de l'existence d'importants fronts pionniers liés au développement des cultures de rente (Brou et al., 2005). Enfin, c'est dans cette zone du Sud-Est qu'est mis en œuvre le projet REDD+ de la Mé, le tout premier projet pilote REDD+ initié par l'État Ivoirien afin de préserver son patrimoine forestier et environnemental.

La végétation du Sud-Est de la Côte d'Ivoire est celle du domaine guinéen. Elle est située dans le secteur ombrophile caractérisé par la forêt dense humide sempervirente de type Eremospatha macrocarpa et Diospyros mannii et dans le secteur mésophile correspondant à la forêt dense humide semi-décidue de type Triplochiton scleroxylon et Khaya ivorensis (Avenard et al., 1971). Le relief est constitué de nombreuses collines dont l'altitude maximale est d'environ $500 \mathrm{~m}$.

\section{Collection d'images satellites}

La méthodologie générale appliquée dans cette étude est basée sur le traitement par classification supervisée des images Sentinel-2 (figure 2). Les images couvrant la zone d'étude correspondent à huit scènes d'images d'après le catalogue Copernicus $^{1}$. Les meilleures images avec très peu ou pas de couvert nuageux ont été sélectionnées et téléchargées (tableau I). Pour l'année de référence 2016, les images ont été acquises le 6 janvier, et le 11 mars pour l'année de référence 2019. Ces deux dates correspondent à la saison la plus sèche et chaude de la zone étudiée.

\section{Prétraitements des images}

Pour les deux années de référence 2016 et 2019, les images Sentinel-2 sont disponibles avec un niveau de prétraitements L1C, c'est-à-dire que ce sont des images orthorectifiées où les valeurs correspondent aux réflectances enregistrées au sommet de l'atmosphère. Elles ont d'abord fait l'objet d'une correction atmosphérique par la méthode DOS1 (Dark Object Subtraction) grâce à l'outil « Semi-automatic Classification Plugin » de QGIS (Leroux et al., 2018 ; Congedo, 2020). Ensuite, pour couvrir la zone d'étude, une mosaïque de huit scènes Sentinel-2 a été produite sur la base des bandes spectrales (10 m et $20 \mathrm{~m}$ de résolution spatiale) rééchantillonnées à $10 \mathrm{~m}$ (tableau I).

\section{Délimitation des données d'apprentissage}

Une première étape a été de définir la typologie des catégories d'occupation et d'usage des terres pour réaliser les cartographies (tableau II). Cette

1 https://www.copernicus.eu/fr 


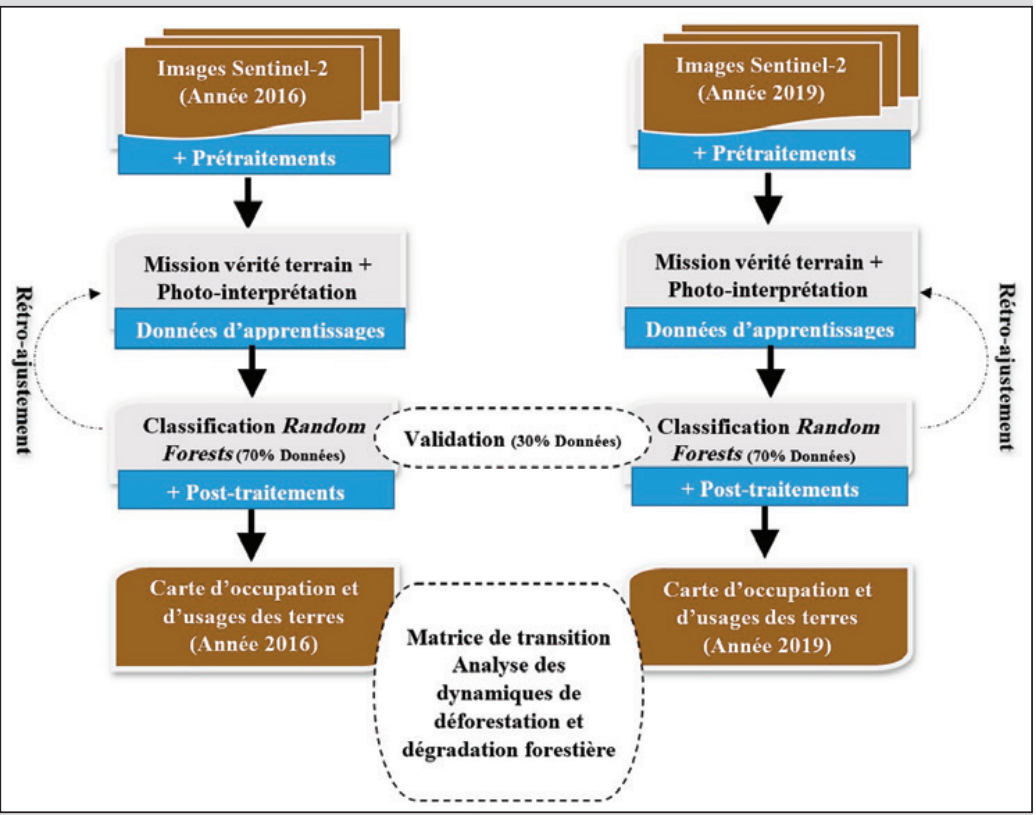

Figure 2.

Présentation synthétique de l'approche méthodologique adoptée. Synthetic presentation of the methodological approach used. d'informations dont les images très haute résolution spatiale (THRS) disponibles sur Google Earth et des relevés issus de deux campagnes de terrain. Ces missions de terrain ont été menées respectivement en février 2017 et mai 2017 dans les trois régions étudiées. Les relevés de terrains comprennent non seulement des points d'identification mais aussi des délimitations de parcelles au GPS. Ils ont concerné l'ensemble des catégories de la typologie, dont les principales cultures de rente (cacao-café, hévéa et palmier à huile). La délimitation des données d'entraînement s'est faite suivant l'apprentissage basé sur les connaissances « d'expert » du terrain en insistant sur les limites des parcelles voisines et de catégories différentes dans une même unité de paysage afin d'aider l'algorithme Random Forest à trouver les bons seuils de différenciation (figure 3). Enfin, les résultats de la photo-interprétation ont été stockés dans une base de données géolocalisées regroupant l'ensemble des données d'apprentissage. Le tableau II présente les caractéristiques de ces données.

\section{Traitements des données}

L'algorithme Random Forests a été calibré sur la base des données d'apprentissage afin de cartographier les 16 catégories d'occupation et d'usage des terres. Les 10 bandes spectrales Sentinel-2 ont constitué les variables en entrée du modèle (pixels pris aléatoirement dans les données d'apprentissages). En effet, l'utilisation de bandes spectrales uniquement dans un modèle Random Forests est un bon compromis entre la précision et le temps de calcul (Pelletier et al., 2016). L'algorithme Random Forests nécessite de définir deux importants paramètres, à savoir le nombre maximum d'arbres de classification souhaité (n) et le

Tableau I.

Caractéristiques générales des bandes spectrales des images Sentinel-2 utilisées. General characteristics of the spectral bands of the Sentinel-2 images used.

\begin{tabular}{|c|c|c|c|c|c|}
\hline Bandes & $\begin{array}{l}\text { Résolution } \\
\text { spatiale }\end{array}$ & $\begin{array}{l}\text { Longueur d'onde } \\
\text { centrale }(\mathrm{nm})\end{array}$ & $\begin{array}{l}\text { Largeur de } \\
\text { la bande }(\mathrm{nm})\end{array}$ & Scènes T30 & Dates d'acquisition \\
\hline 2 & $10 \mathrm{~m}$ & 490 & 65 & \multirow{10}{*}{$\begin{array}{l}\text { NUM NUN NVL NVM } \\
\text { NVN NVP NWL NWM }\end{array}$} & \multirow{10}{*}{$\begin{array}{l}06 / 01 / 2016 \\
\text { et } 11 / 03 / 2019\end{array}$} \\
\hline 3 & & 560 & 35 & & \\
\hline 4 & & 665 & 30 & & \\
\hline 8 & & 842 & 115 & & \\
\hline 5 & $20 \mathrm{~m}$ & 705 & 15 & & \\
\hline 6 & & 740 & 15 & & \\
\hline 7 & & 783 & 20 & & \\
\hline $8 a$ & & 865 & 20 & & \\
\hline 11 & & 1610 & 90 & & \\
\hline 12 & & 2190 & 180 & & \\
\hline
\end{tabular}


Tableau II.

Typologie des catégories d'occupation et d'usage des terres et caractéristiques des données d'apprentissage. Typology of occupation and land use categories and characteristics of learning data.

\begin{tabular}{|c|c|c|c|c|c|c|}
\hline \multirow[t]{2}{*}{ Code } & \multirow[t]{2}{*}{ Nom Court } & \multirow[t]{2}{*}{ Description } & \multicolumn{2}{|c|}{ Données 2016} & \multicolumn{2}{|c|}{ Données 2019} \\
\hline & & & Polygones & Pixels & Polygones & Pixels \\
\hline FD & Forêt dense & Formation naturelle de type primaire & 181 & 41184 & 197 & 42793 \\
\hline$\overline{F G}$ & $\begin{array}{l}\text { Forêt-galerie/ } \\
\text { marécageuse }\end{array}$ & $\begin{array}{l}\text { Formation forestière établie sur des sols hydromorphes } \\
\text { proches des cours d'eau }\end{array}$ & 48 & 5053 & 42 & 3606 \\
\hline FDS & $\begin{array}{l}\text { Forêt dégradée/ } \\
\text { secondaire }\end{array}$ & Formation forestière sous influence de la dégradation & 284 & 35094 & 389 & 55821 \\
\hline $\mathrm{T}$ & Teckeraie & Plantation monospécifique de teck & 7 & 351 & 7 & 377 \\
\hline$\overline{C C}$ & Cacao-café & Zone de cultures de cacao et/ou de café & 379 & 33654 & 504 & 48034 \\
\hline $\mathrm{H}$ & Hévéa & Zone de culture d’hévéa & 268 & 39225 & 429 & 59722 \\
\hline$P$ & Palmeraie & Zone de culture de palmier à huile & 105 & 23504 & 169 & 33370 \\
\hline B & Bananeraie & Zone de culture de bananier & 34 & 4164 & 35 & 4632 \\
\hline $\mathrm{Cll}$ & $\begin{array}{l}\text { Culture/jachère } \\
\text { non différenciée }\end{array}$ & $\begin{array}{l}\text { Zone de cultures non encore différenciées, cultures des } \\
\text { bas-fonds, cultures annuelles et jeunes jachères ( } 3 \text { à } 7 \text { ans) }\end{array}$ & 282 & 46168 & 359 & 47167 \\
\hline A & Ananeraie & Parcelle agricole plantée d’ananas & 33 & 4347 & 28 & 5678 \\
\hline $\mathrm{PE}$ & Plan d'eau & Ensemble des retenues d'eau & 79 & 44065 & 75 & 9113 \\
\hline $\mathrm{ZM}$ & Zone marécageuse & $\begin{array}{l}\text { Terres humides et bourbeuses constituées de marais } \\
\text { et de marécages }\end{array}$ & 51 & 8798 & 49 & 9188 \\
\hline $\mathrm{H}$ & Habitation & Habitats humains & 113 & 10909 & 97 & 12602 \\
\hline $\bar{R}$ & Route & Voies de transport et réseau routier & 108 & 2081 & 132 & 4771 \\
\hline SN & Sol nu & Terrain dépourvu de couvert végétal & 26 & 1150 & 20 & 1347 \\
\hline $\mathrm{N}$ & Nuage & Nuage & 5 & 2232 & 17 & 38290 \\
\hline Total & & & 2003 & 301979 & 2549 & 376511 \\
\hline
\end{tabular}

nombre de variables de prédiction choisies aléatoirement (m) pour chaque nœud des arbres (Breiman, 2001). Nous avons utilisé les valeurs par défaut $(n=500$ et $m=3$ ) qui ont montré des résultats satisfaisants (Rodriguez-Galiano et al., 2012).

Une fois le modèle calibré, l'algorithme a été appliqué pour produire la carte brute d'occupation et d'usage des terres. Cette carte a été faite de manière itérative, c'est-àdire par plusieurs allers et retours (étape de rétro-ajustement des données d'apprentissage) entre la photo-interprétation, la calibration et la production de cartes intermédiaires. L'ensemble des traitements a été réalisé avec le logiciel $R$ et le package randomForest (Liaw et Wiener, 2002).
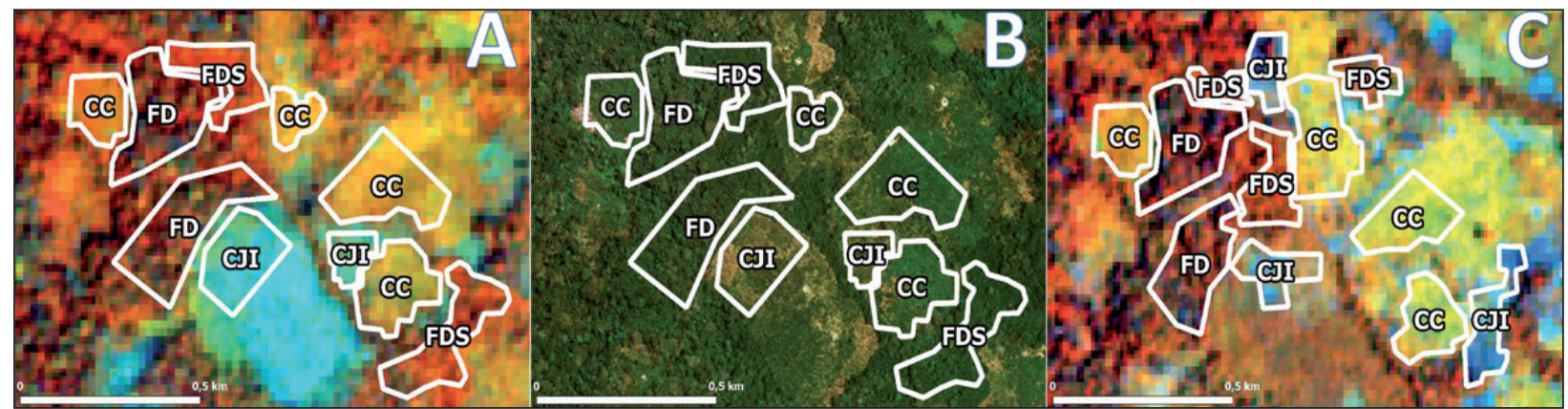

Figure 3.

Photo-interprétation et délimitation des données d'apprentissage sur : A. une image composite Sentinel-2 de 2016 avec un affichage en fausses couleurs (R : bande 8 ; G : bande 5 ; B : bande 4) ; B. une image THRS de Google Earth de 2016 ; C. une image composite Sentinel-2 de 2019 avec un affichage en fausses couleurs (R : bande 8 ; G : bande 5 ; B : bande 4). CC : café-cacao ; FD : forêt dense ; FDS : forêt dégradée ou secondaire; $C J I$ : culture ou jachère Indifférenciée.

Photo-interpretation and delineation of learning data on: A. a 2016 Sentinel-2 composite image with a false colour display (R: Band 8 G: Band 5- B: Band 4); B. a 2016 Google Earth THRS image; C. a 2019 Sentinel-2 composite image with a false colour display (R: Band 8 - G: Band 5 - B: Band 4). CC: coffee-cocoa; FD: dense forest; FDS: degraded or secondary forest; CJl: undifferentiated crop or fallow. 


\section{Évaluation de la qualité des cartographies}

Une validation croisée a été réalisée à partir des outils d'évaluation de la qualité du modèle disponibles dans le package randomForest. L'outil permet de calculer un indicateur de précision globale (variance expliquée) et une matrice de confusion à partir d'une sélection aléatoire d'un échantillon test correspondant à $30 \%$ du jeu de données initial, laissé de côté pendant la phase de calibration, et utilisé pour la validation à chaque itération du modèle (échantillon "Out-Of-the-Bag»; Bylander, 2002).

In fine les indicateurs de précision du modèle (précision globale, coefficient Kappa, précision utilisateur et précision producteur) ont été calculés à partir des matrices de confusion obtenues par la validation croisée. Cette méthode de validation croisée permet d'avoir une estimation non biaisée du taux d'erreur en généralisation sans avoir recours à un échantillon test supplémentaire (Chehata et al., 2015).

\section{Post-traitements}

Une étape de post-traitements qui inclut un filtrage des résultats des classifications a été abordée afin de les nettoyer des « bruits » et potentielles erreurs (pixels isolés) couramment rencontrés dans les images à haute résolution spatiale (El Garouani et al., 2008). Aussi, cette étape a permis de faire correspondre les cartes aux exigences d'unité minimale de cartographie (UMC). L'UMC adoptée est conforme au Code forestier ivoirien de juillet 2019 qui fixe la superficie minimale des forêts à 0,1 ha. La méthodologie qui a été adoptée pour effectuer les post-traitements se résume en deux étapes : un premier passage de filtre convolutif majoritaire de dimension $3 \times 3$ pixels pour réduire le bruit; un second passage de filtre de tamisage d'une taille de 10 pixels, correspondant exactement à 0,1 hectare. Cette UMC a été appliquée pour l'ensemble des catégories d'occupation et d'usage des terres.

\section{Analyse des changements d'occupation et d'usage des terres}

L'analyse des changements d'occupation et d'usage des terres s'est appuyée sur le calcul de deux indicateurs statistiques dont la matrice de transition et le taux de changement entre les deux dates (en $\mathrm{km}^{2}$ et pourcentage). La matrice de transition permet de mettre en évidence les différentes conversions d'occupation et d'usage des terres entre deux dates et de quantifier ces changements (Barima et al., 2016 ; Kpedenou et al., 2016). Cette matrice ne fournit pas d'informations sur la distribution spatiale des changements. Ainsi, une étape de spatialisation des changements a été réalisée pour évaluer la localisation et la pertinence de ces changements. Pour le calcul des taux de changements annuels, la formule standardisée proposée par Puyravaud (2002) a été utilisée :

$T=-\frac{1}{t 2-t 1} \ln \left(\frac{S 2}{S 1}\right) \times 100$

où $\mathrm{S} 1$ et $\mathrm{S} 2$ désignent les superficies de la catégorie d'occupation du sol aux dates t1 et t2.

\section{Résultats}

\section{Évaluation de la qualité des cartes}

Les cartes d'occupation et d'usage des terres de 2016 et de 2019 présentent respectivement des précisions globales de $92 \%$ et $87 \%$ avec des coefficients Kappa de 0,91 et 0,85 . Les matrices de confusion des classifications des images Sentinel-2 de 2016 et 2019 présentent des valeurs élevées de précision utilisateur (PU > $75 \%$ ) pour l'ensemble des catégories d'occupation et d'usage des terres. On observe cependant des confusions plus marquées : d'une part, entre les forêts dégradées ou secondaires et les autres catégories telles que les forêts denses, les cultures de rente (cacao-café et hévéa) et les cultures ou jachères non différenciées pour les deux dates; d'autre part, entre les cultures ou jachères non différenciées et les cultures de rente (cacaocafé et hévéa). Les deux cartes produites à partir de différents jeux de données d'apprentissage ont sensiblement le même ordre de grandeur d'erreur (PU) par catégorie, avec moins de $2,5 \%$ d'écart en moyenne.

\section{Occupations et usages des terres en 2016 et 2019}

Les deux résultats cartographiques montrent que les forêts denses rémanentes restent confinées dans la réserve naturelle de Mabi-Yaya, dans les forêts classées de Bossématié et de N'Guéchié (figure 4). Les estimations indiquent que ces trois forêts protégées renferment à elles seules plus de $30 \%$ des forêts denses des trois régions du Sud-Est du pays. On observe que la forêt classée d'Ehania apparaît comme un bloc agro-industriel. Les cultures de rente de cacao-café sont présentes quasiment sur l'ensemble du Sud-Est. Quant aux cultures industrielles d'hévéa et de palmier à huile, elles dominent dans les parties centre et sud de la zone d'étude.

\section{Changements d'occupation et d'usage des terres entre 2016 et 2019}

L'analyse des changements d'occupation et d'usage des terres sur la période de 2016 à 2019 (tableau IV) montre un recul significatif des formations forestières (forêts denses, forêts-galeries et forêts secondaires) au profit des habitations et infrastructures routières, des cultures de rente (cacao-café, hévéa et palmier à huile) ainsi que des cultures et jachères non différenciées. Les formations forestières sont passées de $8276 \mathrm{~km}^{2}$ en 2016 à $7134 \mathrm{~km}^{2}$ en 2019 , avec un taux annuel de perte de 4,95\% correspondant à la disparition d'environ $400 \mathrm{~km}^{2}$ de formations forestières par an. Les habitations et infrastructures routières ont connu la plus forte expansion (14,57 \%) en passant de $321 \mathrm{~km}^{2}$ à $498 \mathrm{~km}^{2}$ durant la période de 2016 à 2019. Ensuite, les cultures de rente (cacao-café, hévéa et palmier à huile) sont

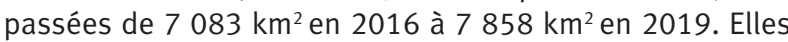
ont donc connu une expansion annuelle de 3,46\%. Enfin, les cultures et jachères non différenciées ont légèrement augmenté, avec un taux annuel d'expansion de 0,39\%, pas-

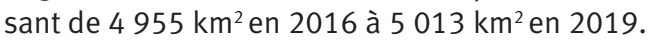


Tableaux III.

Matrices de confusion et précisions des cartes d'occupation et d'usage des terres de 2016 et de 2019 (en nombre de pixels). $\mathrm{PU}$ : précision utilisateur ; PP : précision producteur.

Confusion matrices and accuracies for the 2016 and 2019 land use and occupancy maps (number of pixels).

PU: User Accuracy; PP: Producer Accuracy.

\begin{tabular}{|c|c|c|c|c|c|c|c|c|c|c|c|c|c|c|c|c|c|c|}
\hline 2016 & FD & FG & FDS & $T$ & $\mathrm{CC}$ & H & $\mathbf{P}$ & B & CJI & A & PE & ZM & H & $\mathbf{R}$ & SN & N & Total & PU \\
\hline FD & 11866 & 6 & 320 & 0 & 45 & 44 & 107 & 0 & 32 & 0 & 0 & 0 & 0 & 0 & 0 & 0 & 12420 & 0,96 \\
\hline FG & 106 & 1062 & 192 & 0 & 107 & 35 & 12 & 1 & 40 & 0 & 15 & 1 & 3 & 0 & 0 & 2 & 1576 & 0,67 \\
\hline FDS & 524 & 19 & 8915 & 0 & 331 & 315 & 76 & 8 & 257 & 0 & 0 & 4 & 2 & 0 & 0 & 0 & 10451 & 0,85 \\
\hline$T$ & 0 & 0 & 1 & 88 & 0 & 0 & 0 & 0 & 7 & 0 & 0 & 0 & 0 & 0 & 0 & 0 & 96 & 0,92 \\
\hline$\overline{C C}$ & 29 & 18 & 281 & 0 & 9235 & 136 & 10 & 8 & 326 & 0 & 0 & 65 & 2 & 0 & 0 & 0 & 10110 & 0,91 \\
\hline H & 54 & 6 & 263 & 0 & 161 & 10944 & 53 & 2 & 133 & 0 & 0 & 10 & 1 & 1 & 0 & 0 & 11628 & 0,94 \\
\hline P & 86 & 1 & 118 & 0 & 19 & 111 & 6737 & 0 & 74 & 1 & 0 & 1 & 8 & 0 & 0 & 0 & 7156 & 0,94 \\
\hline B & 0 & 0 & 11 & 0 & 10 & 6 & 0 & 1162 & 18 & 5 & 0 & 1 & 1 & 0 & 1 & 0 & 1215 & 0,96 \\
\hline CJI & 137 & 9 & 320 & 1 & 551 & 146 & 38 & 1 & 12475 & 3 & 0 & 100 & 85 & 0 & 0 & 1 & 13867 & 0,90 \\
\hline A & 0 & 0 & 0 & 0 & 1 & 0 & 0 & 0 & 32 & 1265 & 0 & 3 & 10 & 1 & 0 & 0 & 1312 & 0,96 \\
\hline PE & 58 & 8 & 20 & 0 & 11 & 3 & 4 & 0 & 8 & 0 & 13132 & 0 & 0 & 1 & 0 & 0 & 13245 & 0,99 \\
\hline ZM & 5 & 6 & 27 & 1 & 153 & 3 & 0 & 1 & 120 & 2 & 0 & 2299 & 0 & 0 & 0 & 2 & 2619 & 0,88 \\
\hline H & 0 & 0 & 2 & 0 & 10 & 3 & 1 & 7 & 222 & 8 & 0 & 5 & 3008 & 18 & 2 & 4 & 3290 & 0,91 \\
\hline$R$ & 0 & 0 & 15 & 1 & 3 & 3 & 3 & 0 & 68 & 0 & 0 & 0 & 62 & 453 & 4 & 0 & 612 & 0,74 \\
\hline SN & 0 & 0 & 0 & 0 & 0 & 1 & 1 & 2 & 29 & 1 & 0 & 2 & 17 & 7 & 287 & 0 & 347 & 0,83 \\
\hline $\mathrm{N}$ & 0 & 0 & 2 & 0 & 11 & 0 & 0 & 0 & 0 & 0 & 0 & 0 & 0 & 0 & 0 & 636 & 649 & 0,98 \\
\hline Total & 12865 & 1135 & 10487 & 91 & 10648 & 11750 & 7042 & 1192 & 13841 & 1285 & 13147 & 2491 & 3199 & 481 & 294 & 645 & 90593 & \\
\hline PP & 0,92 & 0,94 & 0,85 & 0,97 & 0,87 & 0,93 & 0,96 & 0,97 & 0,90 & 0,98 & 1,00 & 0,92 & 0,94 & 0,94 & 0,98 & 0,99 & & \\
\hline
\end{tabular}

\begin{tabular}{|c|c|c|c|c|c|c|c|c|c|c|c|c|c|c|c|c|c|c|}
\hline 2019 & FD & FG & FDS & $\mathrm{T}$ & CC & H & $\mathbf{P}$ & B & CJI & A & PE & ZM & H & $\mathbf{R}$ & SN & N & Total & PU \\
\hline FD & 11437 & 3 & 970 & 0 & 119 & 193 & 150 & 5 & 19 & 0 & 2 & 0 & 0 & 3 & 0 & 0 & 12901 & 0,89 \\
\hline FG & 96 & 343 & 344 & 0 & 125 & 102 & 20 & 6 & 59 & 2 & 12 & 6 & 0 & 1 & 0 & 0 & 1116 & 0,31 \\
\hline FDS & 1309 & 1 & 12607 & 0 & 1045 & 1032 & 260 & 21 & 315 & 0 & 3 & 6 & 3 & 5 & 0 & 0 & 16607 & 0,76 \\
\hline$T$ & 0 & 0 & 2 & 71 & 4 & 11 & 2 & 0 & 38 & 0 & 0 & 1 & 0 & 0 & 0 & 0 & 129 & 0,55 \\
\hline$\overline{C C}$ & 153 & 2 & 935 & 0 & 12112 & 398 & 46 & 10 & 731 & 10 & 0 & 41 & 2 & 5 & 0 & 0 & 14445 & 0,84 \\
\hline H & 193 & 2 & 885 & 1 & 545 & 15721 & 142 & 8 & 244 & 1 & 0 & 15 & 2 & 5 & 0 & 0 & 17764 & 0,88 \\
\hline $\mathbf{P}$ & 98 & 1 & 203 & 0 & 55 & 122 & 9457 & 3 & 179 & 0 & 0 & 7 & 4 & 6 & 0 & 0 & 10135 & 0,93 \\
\hline B & 0 & 0 & 14 & 0 & 9 & 21 & 1 & 1309 & 41 & 1 & 0 & 9 & 2 & 2 & 0 & 0 & 1409 & 0,93 \\
\hline CJI & 59 & 0 & 308 & 0 & 667 & 213 & 105 & 10 & 12683 & 21 & 8 & 129 & 66 & 32 & 0 & 0 & 14301 & 0,89 \\
\hline A & 0 & 0 & 2 & 0 & 2 & 10 & 0 & 3 & 79 & 1576 & 0 & 6 & 7 & 2 & 0 & 0 & 1687 & 0,93 \\
\hline$\overline{P E}$ & 15 & 5 & 31 & 0 & 8 & 14 & 2 & 1 & 23 & 2 & 2568 & 3 & 0 & 3 & 0 & 0 & 2675 & 0,96 \\
\hline$\overline{Z M}$ & 2 & 0 & 16 & 1 & 118 & 27 & 11 & 2 & 454 & 6 & 2 & 2053 & 2 & 5 & 0 & 0 & 2699 & 0,76 \\
\hline H & 0 & 0 & 3 & 0 & 4 & 2 & 5 & 0 & 300 & 0 & 0 & 4 & 3413 & 22 & 0 & 9 & 3762 & 0,91 \\
\hline $\mathbf{R}$ & 0 & 0 & 51 & 0 & 25 & 21 & 8 & 4 & 196 & 5 & 0 & 0 & 33 & 1121 & 0 & 0 & 1464 & 0,77 \\
\hline SN & 0 & 0 & 1 & 0 & 0 & 1 & 2 & 0 & 49 & 0 & 0 & 1 & 40 & 6 & 330 & 1 & 431 & 0,77 \\
\hline $\mathrm{N}$ & 0 & 0 & 0 & 0 & 0 & 0 & 0 & 0 & 0 & 0 & 0 & 0 & 0 & 0 & 0 & 11502 & 11502 & 1 \\
\hline Total & 13362 & 357 & 16372 & 73 & 14838 & 17888 & 10211 & 1382 & 15410 & 1624 & 2595 & 2281 & 3574 & 1218 & 330 & 11512 & 113027 & \\
\hline PP & 0,86 & 0,96 & 0,77 & 0,97 & 0,82 & 0,88 & 0,93 & 0,95 & 0,82 & 0,97 & 0,99 & 0,90 & 0,95 & 0,92 & 1,00 & 1,00 & & \\
\hline
\end{tabular}

FD : forêt dense ; FG : forêt-galerie/marécageuse ; FDS : forêt dégradée/secondaire ; T : teckeraie ; CC : cacao-café ; H : hévéa ; P : palmeraie ; B : bananeraie ; CII : culture/jachère non différenciée ; $\mathrm{A}$ : ananeraie ; PE : plan d’eau ; ZM : zone marécageuse ; $\mathrm{H}$ : habitation ; $\mathrm{R}$ : route ; SN : sol nu ; $\mathrm{N}$ : nuage.

\section{Conversions des formations forestières denses}

La matrice de transition a été utilisée pour extraire et analyser plus finement les conversions des formations forestières denses (figure 5), qui comprennent les forêts denses, les forêts-galeries et marécageuses. L'analyse de la carte des changements des formations forestières denses montre que d'importants changements sont localisés essentiellement dans les forêts classées et les aires protégées. L'analyse statistique correspondante (tableau V) indique que $47 \%$ de ces formations ont subi des changements qui se traduisent principalement par des conversions en forêts dégradées ou secondaires (24\%), en cultures et jachères non différenciées (7\%) et en cultures pérennes de cacao-café (4\%). 


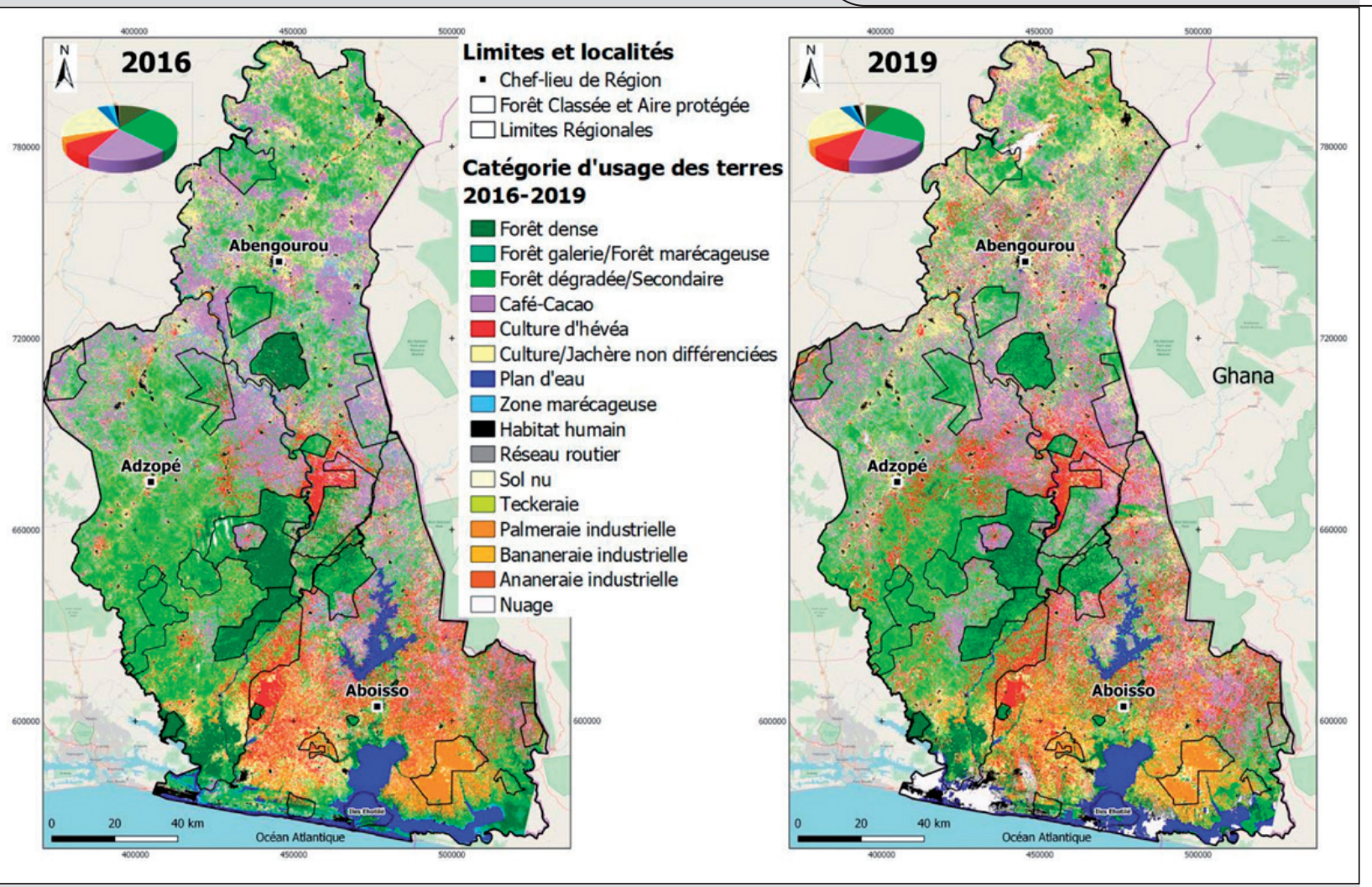

Figure 4.

Cartes d'occupation et d'usage des terres et diagrammes de répartition des types d'usage des terres en 2016 et en 2019 dans le Sud-Est de la Côte d'Ivoire.

Land tenure and land use maps and distribution diagrams of land use types in 2016 and 2019 in south-eastern Côte d'Ivoire.

\section{Tableau IV.}

Dynamique d'occupation et d'usage des terres entre 2016 et 2019 dans les trois régions du Sud-Est de la Côte d'Ivoire.

Land tenure and land use dynamics between 2016 and 2019 in the three south-eastern regions of Côte d'lvoire.

\section{Catégorie d'occupation et d'usage des terres}

\begin{tabular}{|c|c|c|c|}
\hline \multicolumn{2}{|c|}{2016} & \multicolumn{2}{|c|}{2019} \\
\hline Surface $\left(\mathrm{km}^{2}\right)$ & $\%$ & Surface $\left(\mathrm{km}^{2}\right)$ & $\%$ \\
\hline 5630 & 25,65 & 5276 & 24,03 \\
\hline 4955 & 22,58 & 5013 & 22,84 \\
\hline 4435 & 20,20 & 4729 & 21,55 \\
\hline 2381 & 10,85 & 1842 & 8,39 \\
\hline 1873 & 8,53 & 2295 & 10,45 \\
\hline 776 & 3,53 & 834 & 3,80 \\
\hline 783 & 3,57 & 762 & 3,47 \\
\hline 441 & 2,01 & 231 & 1,05 \\
\hline 300 & 1,37 & 363 & 1,65 \\
\hline 265 & 1,21 & 16 & 0,07 \\
\hline 26 & 0,12 & 49 & 0,22 \\
\hline 22 & 0,10 & 33 & 0,15 \\
\hline 21 & 0,10 & 135 & 0,61 \\
\hline 2 & 0,01 & 13 & 0,06 \\
\hline 1 & 0,00 & 0 & 0,00 \\
\hline 40 & 0,18 & 360 & 1,64 \\
\hline 21951 & 100 & 21951 & 100 \\
\hline
\end{tabular}

\section{Conversions des forêts dégradées ou secondaires}

La même analyse a été réalisée pour localiser et quantifier les conversions des formations forestières dégradées ou secondaires (figure 6). Les résultats montrent que ces formations ont connu de grands changements dans toute la zone d'étude, encore une fois essentiellement localisés dans le domaine rural, mais aussi dans les forêts classées et les aires protégées. L'analyse statistique correspondante (tableau $\mathrm{VI}$ ) indique que $49 \%$ de ces formations ont subi des changements, principalement par des conversions en cultures pérennes de cacao-café (16\%), en cultures et jachères non différenciées (15\%) ou encore en culture d’hévéa (9\%). 


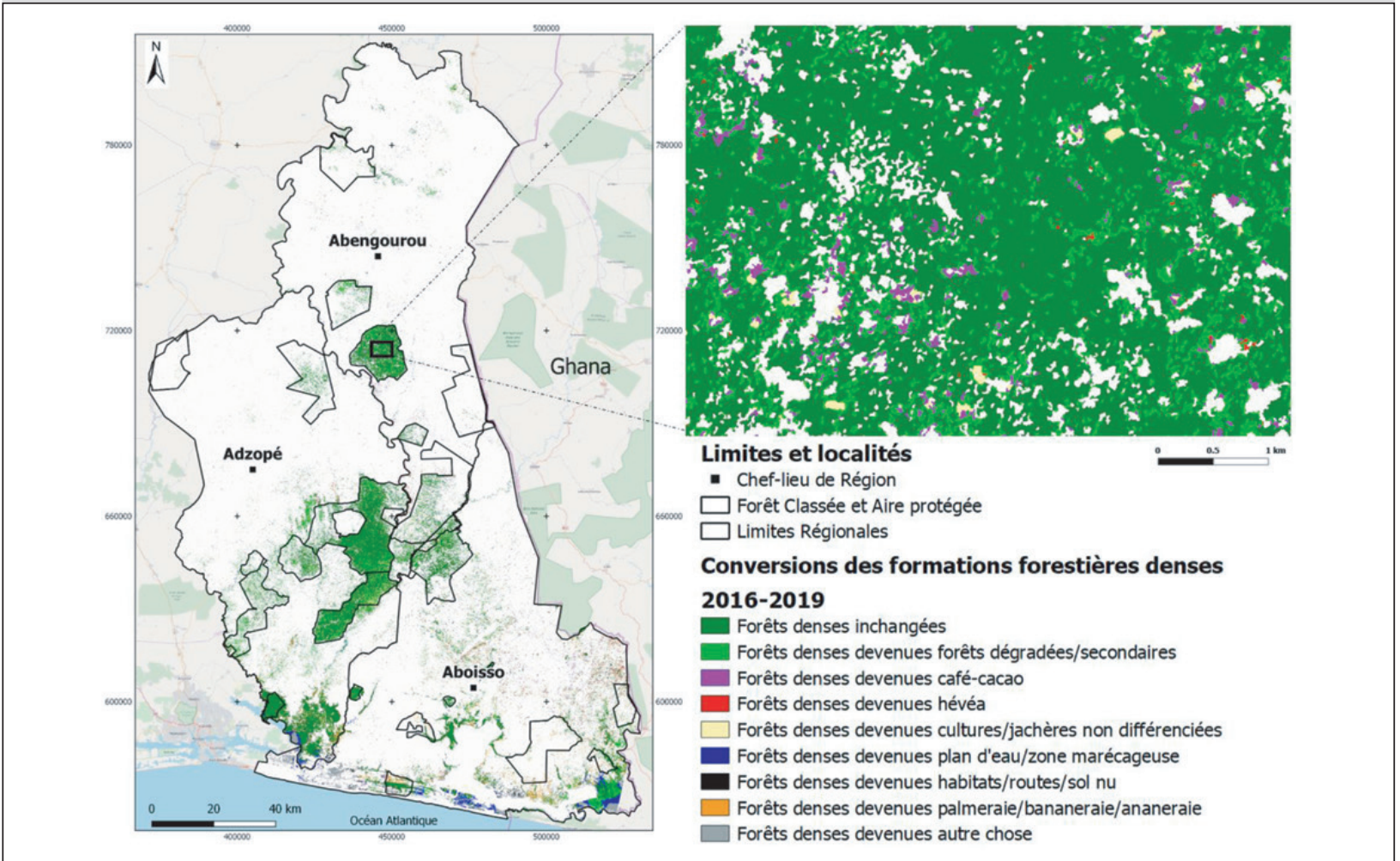

Figure 5 .

Conversions des formations forestières denses entre 2016 et 2019 dans le Sud-Est de la Côte d'Ivoire. Conversions of dense forest formations between 2016 and 2019 in south-eastern Côte d'lvoire.

\section{Tableau V.}

Matrice de transition des formations forestières denses (forêts denses et forêts-galeries/marécageuses) entre 2016 et 2019 dans le Sud-Est de la Côte d'Ivoire.

Transition matrix of dense forest formations (dense forests and gallery/ marsh forests) between 2016 and 2019 in south-eastern Côte d'Ivoire.

2019

\begin{tabular}{|c|c|c|}
\hline \multirow[t]{2}{*}{ 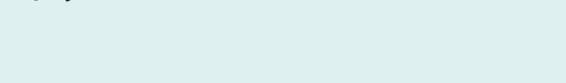 } & \multicolumn{2}{|c|}{ et forêt-galerie/marécageuse } \\
\hline & Surface $\left(\mathrm{km}^{2}\right)$ & $\%$ \\
\hline Forêt dense et forêt-galerie/marécageuse & 1393 & 53 \\
\hline Forêt dégradée/secondaire & 630 & 24 \\
\hline Culture/jachère non différenciée & 185 & 7 \\
\hline Culture de cacao-café & 101 & 4 \\
\hline Autres (teckeraie et nuage) & 82 & 3 \\
\hline Cultures d’hévéa & 79 & 3 \\
\hline Palmeraie, bananeraie et ananeraie & 74 & 3 \\
\hline Plan d'eau et zone marécageuse & 78 & 3 \\
\hline Habitat, route et sol nu & 27 & 1 \\
\hline Total & 2648 & 100 \\
\hline
\end{tabular}

\section{Discussion}

\section{Évaluation de la qualité des cartes}

La validation croisée des deux cartographies (précisions globales de $92 \%$ et $87 \%$ et coefficients Kappa de 0,91 et 0,85) indique que les cartes ont des niveaux de qualité satisfaisants (Pontius, 2000). Ils sont supérieurs aux indicateurs obtenus pour la carte d'occupation du sol de 2016 au niveau national (BNETD, 2019), estimés à $73 \%$ à partir d'une évaluation externe (IGN, 2019). On observe ainsi des valeurs très élevées de précision utilisateur (PU > 75 \%). Bien qu'il s'agisse d'échantillons tirés aléatoirement et agrégés pour de nombreuses itérations (validation croisée), les observations utilisées peuvent être géographiquement proches les unes des autres. Il s'agit du phénomène d'autocorrélation spatiale qui génère des indicateurs souvent optimistes, connu pour ce type de validation et souvent ignoré. Pour éviter ce problème lié à la validation croisée, une validation indépendante et externe au processus de cartographie est très souvent nécessaire. D’après les recommandations 

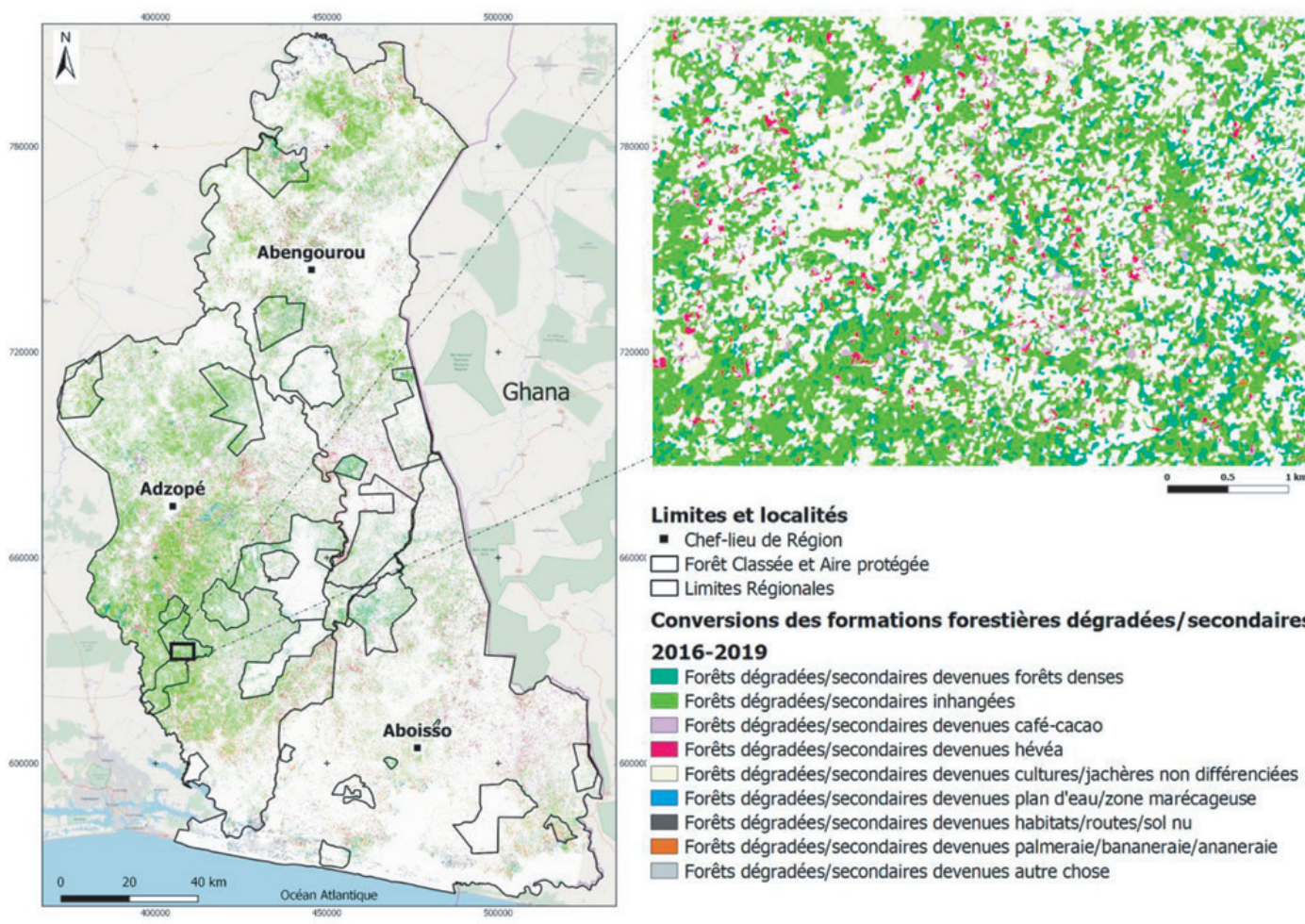

Conversions des formations forestières dégradées/secondaires 2016-2019

Forêts dégradées/secondaires devenues forêts denses

- Forêts dégradées/secondaires inhangées

Forêts dégradées/secondaires devenues café-cacao

Forêts dégradées/secondaires devenues hévéa

Forêts dégradées/secondaires devenues cultures/jachères non différenciées

Forêts dégradées/secondaires devenues plan d'eau/zone marécageuse

- Forêts dégradées/secondaires devenues habitats/routes/sol nu

Forêts dégradées/secondaires devenues palmeraie/bananeraie/ananeraie

$\square$ Forêts dégradées/secondaires devenues autre chose

\section{Figure 6.}

Conversions des formations forestières dégradées ou secondaires entre 2016 et 2019 dans le Sud-Est de la Côte d'Ivoire. Conversions of degraded or secondary forest formations between 2016 and 2019 in South-East Côte d'Ivoire.

internationales (Olofsson et al., 2014 ; GOFC-GOLD, 2016), la validation externe nécessite des points d'observation de référence issus de campagnes de terrain ou des observations par photo-interprétation sur la base d'images dont la résolution permet d'identifier clairement l'usage des terres (images THRS $<1 \mathrm{~m}$ ). Le premier cas est beaucoup plus réaliste sur de petites surfaces mais des difficultés pour garantir une bonne représentativité spatiale et liées au coût se posent

\section{Tableau VI.}

Matrice de transition des formations forestières dégradées ou secondaires entre 2016 et 2019 dans le Sud-Est de la Côte d'Ivoire. Transition matrix of degraded or secondary forest formations between 2016 and 2019 in South-East Côte d'Ivoire.

2019

Culture de café-cacao

Culture/Jachère non différenciée

Cultures d'hévéa

Forêt dense et forêt-galerie/marécageuse

Palmeraie, bananeraie et ananeraie

Autres (teckeraie et nuage)

Habitat, route et sol nu

Plan d'eau et zone marécageuse

Total
2016

Forêt dégradée/secondaire Surface $\left(\mathrm{km}^{2}\right)$

$\%$

\begin{tabular}{|r|r|}
\hline 2844 & 51 \\
\hline 906 & 16 \\
\hline 824 & 15 \\
\hline 492 & 9 \\
\hline 297 & 5 \\
\hline 104 & 2 \\
\hline 69 & 1 \\
\hline 55 & 1 \\
\hline 30 & 1 \\
\hline 5621 & 100 \\
\hline
\end{tabular}

pour des cartographies à large échelle. Le second cas se présente souvent, à l'instar de l'outil Collect Earth de la FAO qui facilite ce processus de collecte de données de référence (Bey et al., 2016). Dans cette étude, il n'a pas été possible de conduire une telle évaluation car pour les deux années de référence 2016 et 2019, aucune donnée THRS n'a été acquise ou disponible (couverture complète) sur Google Earth. Cette observation est par ailleurs valable pour toute étude diachronique historique ou récente dont l'achat d'images THRS (entre 5 et 10 euros/ $\mathrm{km}^{2}$ ) n'a pas été anticipé ou réalisé. En résumé, cette validation croisée ne peut pas être considérée comme une estimation indépendante de la qualité des deux cartes mais elle donne un aperçu de leur fiabilité et des indications pertinentes sur les confusions entre les catégories sans avoir recours à un échantillon test supplémentaire (Chehata et al., 2015). 


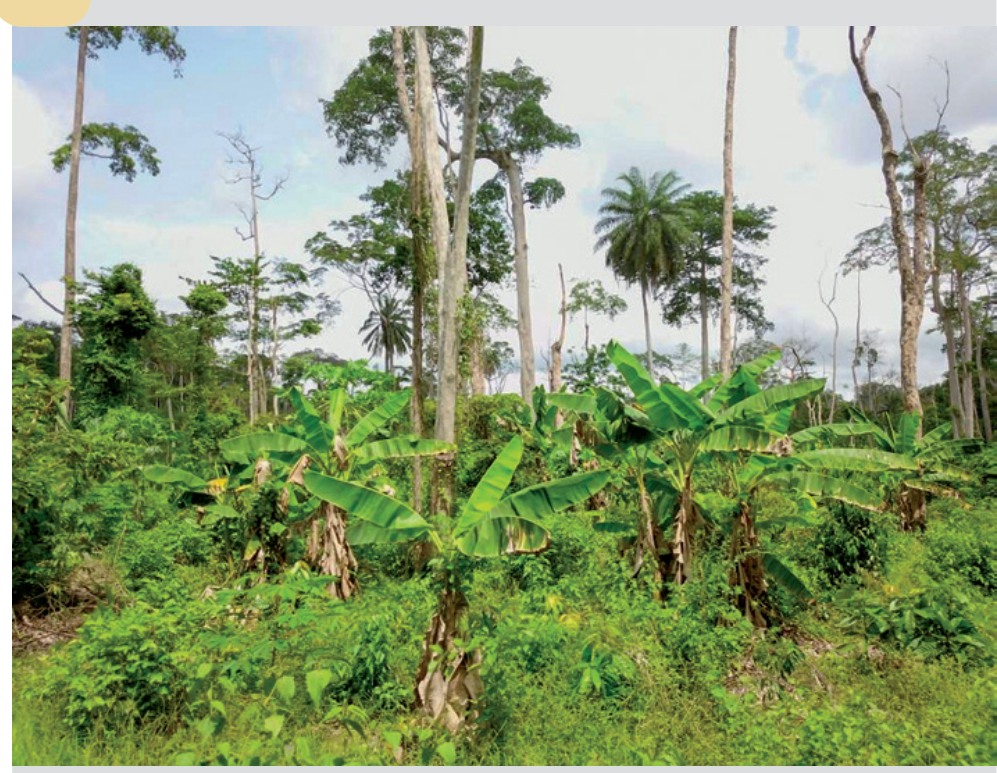

Photo 2.

Paysage de forêt fortement dégradée et mosaïque de cultures (forte hétérogénéité).

Heavily degraded forest landscape and cultural mosaic

(strong heterogeneity).

Photo T. A. Ouattara.

\section{Utilisation du modèle Random Forests}

La qualité d'un modèle Random Forests est très dépendante de la qualité des données d'apprentissage (Gislason et al., 2006). Ces données doivent être représentatives des catégories d'occupation et d'usage des terres avec une distribution spatiale couvrant l'ensemble de la zone d'étude. Elles doivent également être en nombre suffisant afin de permettre une meilleure prise en compte de la variabilité spectrale des catégories à l'échelle locale (Grinand et al., 2013). L'ajout de parcelles tend à améliorer continuellement les résultats jusqu'à un certain seuil où la carte ne montre plus d'amélioration significative. Certains auteurs ont ainsi observé qu'à partir d'un certain seuil il devient superflu de rajouter des données d'apprentissage pour améliorer les résultats (Pelletier et al., 2016). Dans cette étude, pour garantir la bonne qualité de ces données, la délimitation s'est faite à partir des connaissances " d'expert » du terrain et en insistant sur les limites entre les parcelles voisines dans une même unité de paysage (Grinand et al., 2013 ; Rakotomala et al., 2015). Malgré cet effort, il a été difficile d'obtenir une distribution équitable des données d'apprentissage au sein des catégories. Cela est aussi dû à la taille des catégories sur la zone étudiée. Une autre approche consiste à échantillonner des points de manière aléatoire ou régulière pour l'identification des données d'apprentissage. Bien que plus robuste statistiquement, la limite réside dans le fonctionnement intrinsèque de Random Forests qui s'appuie sur des arbres de décision. Ces arbres sont une succession de séparations binaires des valeurs des variables en entrée du modèle (ici réflectance des images satellites) ; l'algorithme détermine automatiquement les seuils de différenciation des catégories d'occupation du sol entre elles. Les échantillons de points très éloignés les uns des autres ne permettent pas de fournir à l'algorithme les informations nécessaires du passage d'une catégorie d'occupation du sol à une autre (exemple d'une forêt dense à forêt dégradée ou à une parcelle de cacao-café). Le travail de photo-interprétation réalisé dans la zone d'étude est considérable, avec plus de 2000 polygones (taille moyenne 1,5 ha) pour chacune des dates, et permet d'assurer la consistance et la pertinence spatiale des cartes produites.

\section{Analyse des confusions}

Les principales confusions se situent entre les forêts dégradées ou secondaires et les autres catégories telles que les forêts denses, les cultures de rente (cacao-café et hévéa) et les cultures ou jachères non différenciées. Cela traduit la complexité et la forte hétérogénéité des formations forestières observées. Cela a d'ailleurs été une difficulté dans le processus même de photo-interprétation sur les images Sentinel-2. Cette hypothèse explicative a été mentionnée par Dibi N’Da et al. (2008) et Jofack Sokeng et al., (2019). À titre d'illustration, la photo 2 présente un paysage de forêt fortement dégradé et des mosaïques de cultures (forte hétérogénéité). En outre, les cultures ou jachères non différenciées pourraient renfermer de très jeunes plantations de cacao et d'hévéa difficilement identifiables sur les images Sentinel-2. Cela pourrait être à l'origine des confusions entre les cultures ou jachères non différenciées et les cultures pérennes (cacaocafé et hévéa). Malgré la sélection de la meilleure image disponible sur les années d'étude, la persistance de nuages et des ombres portées réduisent les capacités de discrimination des modes d'occupation et d'usage des terres.

\section{Dynamique de déforestation et de dégradation des forêts}

Pour les trois régions du Sud-Est de la Côte d'Ivoire, le taux annuel de déforestation a été estimé à 4,95\% entre 2016 et 2019. Il s'agit d'un des taux de déforestation les plus élevés au monde qui risque d'aboutir à la disparition de l'intégralité des forêts primaires humides du pays en 2024 (Commission européenne, 2019). Ce taux est à mettre en perspective avec celui estimé par le BNETD (2016) ainsi que la FAO, SEP-REDD+ (2017), entre 2000 et 2015, estimé à $2,66 \%$ par an pour l'ensemble du territoire national et à $3,73 \%$ par an pour les mêmes régions du Sud-Est. L'étude du BNETD s'est appuyée sur les images Landsat (30 m) et a concerné l'étude de la déforestation de forêts denses. La présente étude a également intégré la déforestation de forêts dégradées ou secondaires afin de tenir compte du couvert forestier dans son ensemble. Il s'agit d'une avancée importante car le territoire concerné par l'étude correspond en grande partie à l'ancienne boucle du cacao, c'est-à-dire la zone originelle d'introduction du cacao à la fin du XIX ${ }^{e}$ siècle (Oszwald et al., 2007). Dans cette zone, de très nombreuses cacaoyères vieillissantes ont été abandonnées par leurs propriétaires et ont donc été largement recolonisées par des espèces arborées au cours des dernières décennies (Oszwald et al., 2007). La proportion de forêts dégradées y est donc beaucoup plus importante que dans le reste du pays, comme le montrent les résultats de cette étude. 


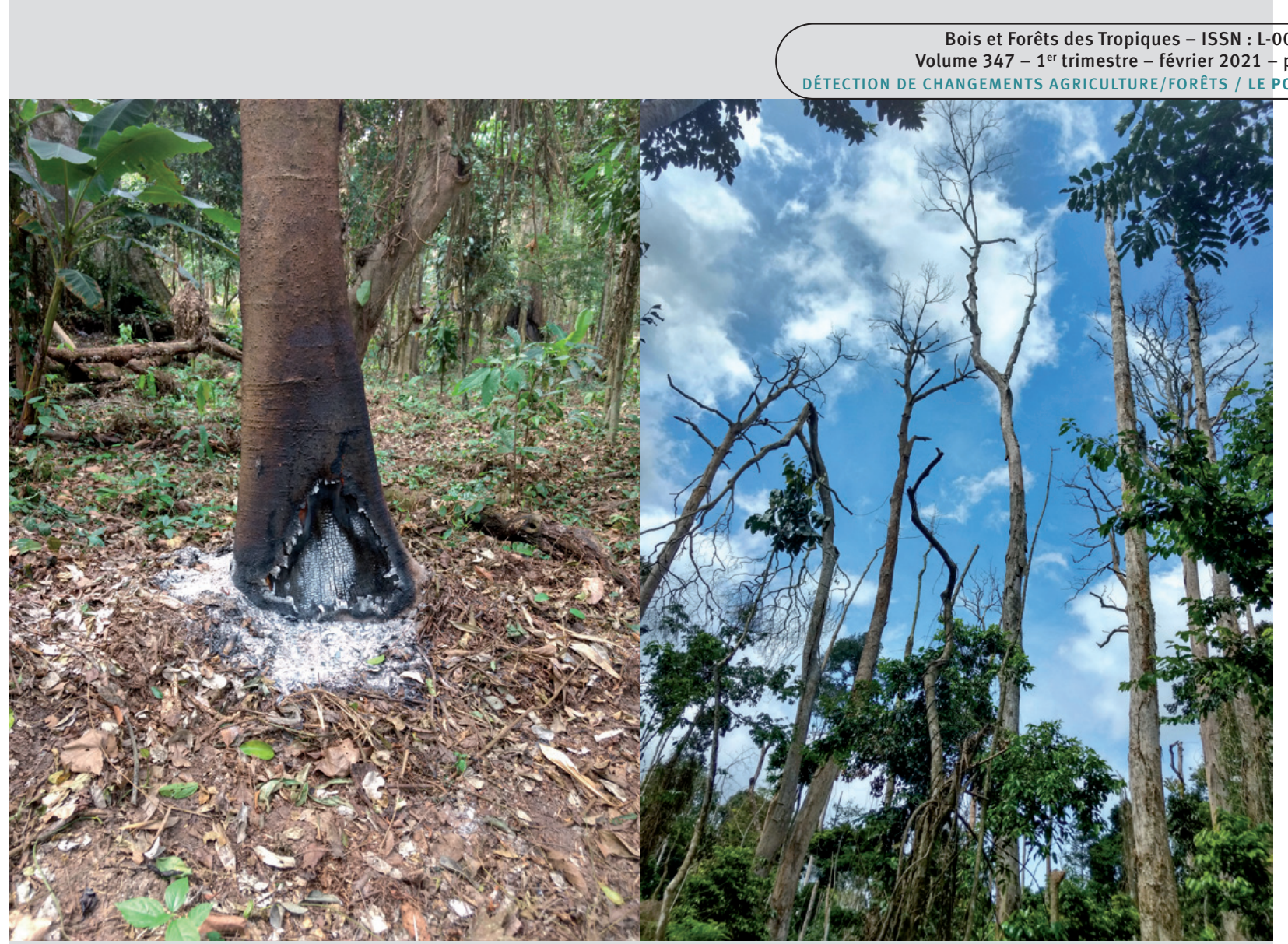

Photos 3.

Mise à feu d'un arbre dans la forêt classée de la Bossématié à la suite de l'installation de la culture du cacao.

(Vue au sol et vue vers le haut montrant la disparition du feuillage.)

Setting fire to a tree in the classified forest of Bossématié following the installation of cocoa cultivation.

(Ground view and upward view showing the disappearance of the foliage).

Photo T. A. Ouattara.

Par ailleurs, c'est aussi au cœur de cette ancienne boucle du cacao que se trouvent certaines forêts protégées du pays encore relativement bien préservées, comme le montrent les résultats, avec plus de $50 \%$ des forêts naturelles encore présentes dans ces périmètres. Ces zones exercent un fort pouvoir d'attraction pour les cacaoculteurs en quête de terres, à l'instar de ceux issus du Parc national du Mont Péko en 2016 suite aux opérations de déguerpissement menées par le gouvernement de Côte d'Ivoire (Ousmane et al., 2020).

Pour éviter de se faire repérer à l'intérieur des forêts classées, les cacaoculteurs détruisent le moins possible la végétation existante pendant les premières années de la création d'une exploitation agricole. À mesure que les plantules se développent, les gros arbres sont progressivement dévitalisés sur pied par le feu (photos 3) pour répondre aux besoins croissants de lumière des jeunes cacaoyers. En l'espace de quelques années seulement, on assiste à la dégradation rapide des forêts denses initiales, rapidement converties en plantations pures de cacao. Ce processus de conversion des forêts primaires en cacaoculture (figure 7) via une brève phase de dégradation a aussi été observé par Barima et al. (2016). La proportion élevée (47\%) de forêts denses concernées par ce processus explique en partie leur confusion avec les cultures et les jachères non différenciées mentionnées dans cette étude.

\section{Facteurs directs de déforestation et de dégradation des forêts}

Les résultats de cette étude mettent en lumière le rôle important de l'hévéaculture dans la réduction du couvert forestier. Cette observation a également été rapportée par Vaudry et al. (2016) qui ont fait une analyse qualitative des facteurs de dégradation et de déforestation dans la même région. Ce phénomène est à mettre en lien avec la forte baisse des coûts du latex qui a succédé à la période de la « fièvre de l'hévéa » de 2011 à 2013, occasionnant un pic de déforestation au profit de l'hévéa. Ces travaux viennent également renforcer ceux de Ruf (2012), qui a observé que l'hévéa succède plus souvent aux forêts dégradées et secondaires (9\% des conversions) qu'aux forêts denses (3\%).

Les résultats corroborent également le lien étroit qui existe entre les coûts des produits agricoles sur les marchés internationaux et le rythme de dégradation et de déforestation en Côte d'Ivoire (Ruf, 2012). En effet, les prix élevés offerts aux cacaoculteurs entre 2016 et 2019 expliquent la dynamique de l'hévéa précitée. Ainsi, la cacaoculture est redevenue la principale cause de déforestation. Et ceci quel que soit le type de forêt : forêts denses ( $4 \%$ des conversions) ou forêts dégradées et secondaires (16\% des conversions) (figure 7). 

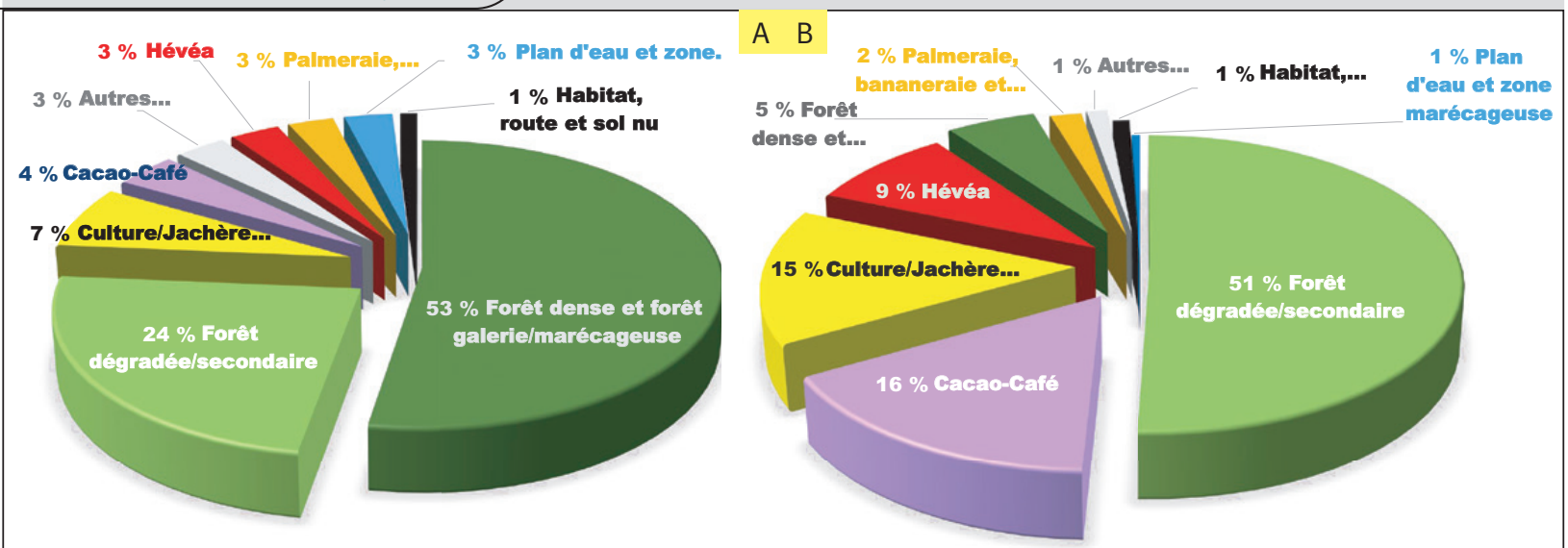

Figure 7.

Analyse des conversions forestières entre 2016 et 2019 concernant : A. les formations forestières denses ;

B. les forêts dégradées ou secondaires.

Analysis of forest conversions between 2016 and 2019 regarding: A. dense forest formations;

$B$. degraded or secondary forests.

\section{Vers un système de suivi des terres en Côte d'Ivoire ?}

Dans le cadre de sa stratégie nationale REDD+, le ministère de l'Environnement et du Développement durable (MINEDD) a posé les bases d'un système de surveillance spatiale des terres (SST). Les réflexions en cours sur les choix techniques pourraient bénéficier des enseignements tirés de la présente étude. En premier lieu, les résultats de ces travaux démontrent qu'il est possible, avec des niveaux d'incertitude satisfaisants, de détecter la déforestation des forêts dégradées et secondaires en plus des forêts denses. Cela permettrait d'affiner notablement le Niveau d'émissions de référence des forêts (NERF) transmis par la Côte d'Ivoire à la Convention-cadre des Nations unies sur les changements climatiques (CCNUCC) (SEP-REDD+, 2017). De plus, ces travaux montrent que ce NERF pourrait également être enrichi avec des données relatives à la détection de la dégradation des forêts, qu'elle soit issue de l'exploitation non durable du bois ou bien de la mutation progressive des forêts denses en cultures pérennes. Au-delà, cela pourrait aider à concrétiser l'Initiative Cacao et Forêts (WCF, 2020) qui, à l'instar du Ghana, envisage de doter la Côte d'Ivoire d'un système performant de suivi des forêts.

D'un point de vue technique, il ne faut pas occulter les difficultés d'acquisition d'images Sentinel-2 exploitables, au regard des fortes couvertures nuageuses en zone tropicale et en particulier en Côte d'Ivoire (présence de cirrus, cumulo-nimbus ou de brume sur l'image). Comme indiqué plus haut, cela affecte le résultat de la cartographie et ce même après l'utilisation d'outils spécifiques pour réduire ces effets. Une solution consisterait à utiliser d'autres outils récemment développés et mis à disposition d'un large public, qui permettent de traiter un volume considérable de données satellites sur une série temporelle dense (ex. Google Earth Engine, SEPAL). Ces outils permettent, entre autres, de produire des compositions d'images "sans nuage ", sur une période donnée et en intégrant des masques de nuages et ombres (Pimple et al., 2018). Une autre solution serait d'avoir recours aux données radar Sentinel-1 Jofack Sokeng et al., 2019). Ces données ont l'avantage de ne pas dépendre du soleil et de ne pas être influencées par les nuages. Cependant, la limite est la saturation du signal lorsque la végétation est trop dense, ce qui est souvent le cas en zone tropicale (Mitchard et al., 2011).

Dans le cadre du déploiement d'un SST, l'usage des drones permettrait de fournir une information précieuse pour compléter le suivi des forêts. En effet, compte tenu de l'amélioration régulière de leur autonomie et de l'agilité de l'acquisition, les drones présentent un bon potentiel pour la détection précoce des ouvertures de la canopée grâce à une très bonne résolution spatiale de l'ordre du centimètre (Semeki Ngabinzeke et al., 2016, 2018). Enfin, les solutions Lidar (en plein essor à l'instar de ICESAT-2/GLAS) mériteraient en particulier d'être testées pour la détection précoce de la disparition du sous-étage de la forêt (Fayad et al., 2014). En effet, il s'agit d'une limite majeure des outils et méthodes de télédétection actuels que de détecter les parcelles de cacao sous ombrage.

Les technologies mentionnées ci-dessus permettraient à la Côte d'Ivoire de disposer d'outils innovants adaptés à son contexte agroforestier et pour la mise en œuvre de ses objectifs ambitieux de développement durable.

\section{Conclusion}

Cette étude a permis de produire des statistiques récentes et fiables sur les types d'occupation et d'usage des terres dans trois régions du Sud-Est de la Côte d'Ivoire conformément à la nomenclature nationale.

L'analyse des changements entre 2016 et 2019 a permis de chiffrer le rythme de conversion des forêts denses et des forêts dégradées ou secondaires. Cette analyse a mis en évidence les processus de dégradation progressive des forêts denses avant que les cultures pérennes de cacaocafé, d'hévéa ou de palmier à huile ne soient détectables. Ces travaux ont aussi permis d'identifier et de quantifier les principaux facteurs de déforestation, confirmant les études précédentes. Il s'agit d'une étude pionnière en Côte d'Ivoire en ce qui concerne l'analyse diachronique de l'occupation et de l'usage des terres à partir d'images Sentinel-2 et de l'algorithme d'apprentissage machine Random Forests. 
Les principales difficultés rencontrées concernent la persistance du couvert nuageux qui réduit considérablement les fenêtres d'acquisition d'images satellites optiques; elles pourraient être contournées en partie grâce à l'utilisation des nouveaux outils de composition d'images à partir de séries temporelles pour fournir des images sans nuage.

La méthodologie développée dans cette étude, par son potentiel de déploiement à grande échelle et à moindre coût, pourrait grandement intéresser les structures en charge du développement d'un système de surveillance spatiale des terres (SST) et appuyer les politiques de développement durable.

\section{Remerciements}

Cette étude a été réalisée dans le cadre du projet REDD+ de la Mé, financé par les Contrats de désendettement et de développement conclus entre la Côte d'Ivoire et la France, et mis en œuvre par Nitidæ en étroite collaboration avec le Secrétariat exécutif permanent de la REDD+ de Côte d'Ivoire. Ce travail s'inscrit aussi dans le cadre de la thèse de doctorat de l'auteur correspondant, sous la direction du CURAT, de l'INP-HB et de Nitidæ.

\section{Références}

Avenard J.-M., Eldin M., Girard G., Sircoulon I., Touchebeuf P., Guillaumet J.-L., et al., 1971. Le milieu naturel de la Côte d'Ivoire. Paris, France, Orstom, coll. Mémoires de l'Orstom, 50, 391 p. https:// www.documentation.ird.fr/hor/fdi:16368

Barima Y. S. S., Barbier N., Bamba I., Traoré D., Lejoly J., Bogaert J., 2009. Dynamique paysagère en milieu de transition forêt-savane ivoirienne. Bois et Forêts des Tropiques, 299 (1) : 15-25. https:// doi.org/10.19182/bft2009.299.a20419

Barima Y. S. S., Kouakou A. T. M., Bamba I., Sangne Y. C., Godron M., Andrieu J., et al., 2016. Cocoa crops are destroying the forest reserves of the classified Forest of Haut Sassandra (Ivory Coast). Global Ecology and Conservation, 8: 85-98. https://doi.org/10.1016/j. gecco.2016.08.009

Bey A., Díaz S.-P. A., Maniatis D., Marchi G., Mollicone D., Ricci S., et al., 2016. Collect Earth: Land Use and Land Cover Assessment through Augmented Visual Interpretation. Remote Sensing, 8 (10): 807. https://doi.org/10.3390/rs8100807

BNETD, 2016. Réalisation d'une étude sur l'identification, l'analyse et la cartographie des causes de la déforestation et de la dégradation des forêts en Côte d'ivoire. Rapport technique. Abidjan, Côte d'Ivoire, BNETD, 104 p.

BNETD, 2019. Maîtrise d'œuvre pour la mise en place du système de surveillance spatiale des terres de la Côte d'ivoire. Rapport technique. Abidjan, Côte d'Ivoire, BNETD, 100 p.

Breiman L., 2001. Random Forests. Machine Learning, 45 (1): 5-32. https://doi.org/10.1023/A:1010933404324

Brou Y. T., Oszwald J., Bigot S., Servat E., 2005. Risques de déforestation dans le domaine permanent de l'État en Côte d'Ivoire : quel avenir pour ces derniers massifs forestiers? Télédétection, 5 (1-2-3): 263-275. https://www.documentation.ird.fr/hor/fdi:010047889 Bylander T., 2002. Estimating generalization error on two-class datasets using out-of-bag estimates. Machine Learning, 48: 287297. https://doi.org/10.1023/A:1013964023376

Chehata N., Ghariani K., Le Bris A., Lagacherie P., 2015. Délimitation des parcelles agricoles par classification d'images Pléiades. Revue Française de Photogrammétrie et de Télédétection, 209 : 165-171. http://recherche.ign.fr/labos/matis/pdf/articles_revues/2015/ RFPT209 chehata.pdf

Commission européenne, 2019. Communication de la Commission au Parlement européen, au Conseil, au Comité économique et social européen et au Comité des régions. Renforcer l'action de l'UE en matière de protection et de restauration des forêts de la planète. Commission européenne, $12 \mathrm{p}$.

Congedo L., 2020. Semi-Automatic Classification Plugin Documentation. Release 7.0.0.1. Document technique, 194 p. http://dx.doi. $\mathrm{org} / 10.13140 / R G .2 .2 .25480 .65286 / 1$
Dibi N'Da H., N’Guessan E. K., Wajda M. E., Affian K., 2008. Apport de la télédétection au suivi de la déforestation dans le Parc National de la Marahoué (Côte d'Ivoire). Bulletin - Société Française de Photogrammétrie et de Télédétection, 8 (1) : 17-34. https://halshs. archives-ouvertes.fr/halshs-00386032/document

FAO, 2010. Forest Resources Assessment. Rapport principal. Rome, Italy, FAO, $341 \mathrm{p}$.

FAO, SEP-REDD+, 2017. Données forestières de base pour la REDD+ en Côte d'Ivoire : Cartographie de la dynamique forestière de 1986 à 2015. Rome, Italie, FAO, 32 p. https://t.co/CeraHO4JOs

Fayad I., Bagdhadi N., Bailly J. S., Barbier N., Gond V., Mahmoud E. H., et al., 2014. Canopy Height Estimation in French Guiana with LiDAR ICESat/GLAS Data Using Principal Component Analysis and Random Forest Regressions. Remote Sensing, 6 (12): 11883-11914. https://doi.org/10.3390/rs61211883

El Garouani A., Chen H., Lewis L., Tribak A., Abharour M. 2008. Cartographie de l'utilisation du sol et de l'érosion nette à partir d'images satellitaires et du SIG IDRISI au Nord-Est du Maroc. Revue Télédétection, 8 (3) : 193-201. https://hal.archives-ouvertes.fr/ hal-00434258

Gislason P. O., Benediktsson J. A., Sveinsson J. R., 2006. Random Forests for land cover classification. Pattern Recognition Letters, 27 (4): 294-300. https://doi.org/10.1016/j.patrec.2005.08.011

GOFC-GOLD, 2016. A sourcebook of methods and procedures for monitoring and reporting anthropogenic greenhouse gas emissions and removals associated with deforestation, gains and losses of carbon stocks in forests remaining forests, and forestation. GOFC-GOLD Report version COP22-1. GOFC-GOLD Land Cover Project Office, Wageningen University, The Netherlands, 268 p. http://www.gofcgold.wur.nl/redd/sourcebook/GOFC-GOLD Sourcebook.pdf

Grinand C., Rakotomalala F., Gond V., Vaudry R., Bernoux M., Vieilledent G., 2013. Estimating deforestation in tropical humid and dry forests in Madagascar from 2000 to 2010 using multi-date Landsat satellite images and the random forests classifier. Remote Sensing of Environment, 139: 68-80. http://dx.doi.org/10.1016/j. rse.2013.07.008

IGN, 2019. Résultats statistiques finaux de la base de données SST dans le cadre du processus de validation. Rapport final. Paris, France, IGN, $21 \mathrm{p}$.

Jofack Sokeng V., Akpa Y. L., Assoma T., Kouamé F., Corgne S. Rudant J.-P., et al., 2019. Suivi par télédétection des affectations des terres pour la promotion d'une agriculture intégrée au développement forestier en Côte d'Ivoire. Conférence OSFACO : Des images satellites pour la gestion durable des territoires en Afrique, 13-15 mars 2019, Cotonou, Bénin, 17 p. https://hal.archives-ouvertes.fr/ hal-02189403

Kpedenou K. D., Boukpessi T., Tchamie T. T. K., 2016. Quantification des changements de l'occupation du sol dans la Préfecture de Yoto (Sud-Est Togo) à l'aide de l'imagerie satellitaire Landsat. Revue des Sciences de l'Environnement, 13 : 137-156. https://hal. archives-ouvertes.fr/hal-01409418

Leroux L., Congedo L., Bellón B., Gaetano R., Bégué A., 2018. Land Cover Mapping Using Sentinel-2 Images and the Semi-Automatic Classification Plugin: A Northern Burkina Faso Case Study. In: Baghdadi N., Mallet C., Zribi M. (eds). QGIS in Remote Sensing SET. Vol. 2: QGIS and Applications in Agriculture and Forest. Wiley, 131 165. https://doi.org/10.1002/9781119457107.ch4

Li H., Leung K.-S., Wong M.-H., Ballester P. J., 2014. Substituting random forest for multiple linear regression improves binding affinity prediction of scoring functions: Cyscore as a case study. BMC Bioinformatics, 15 (291). https://doi.org/10.1186/1471-2105-15-291

Liaw A., Wiener M., 2002. Classification and Regression by randomForest. R News, 2: 18-22. https://cogns.northwestern.edu/ cbmg/LiawAndWiener2002.pdf

Lima T. A., Beuchle R., Langner A., Grecchi R. C., Griess V. C., Achard F., 2019. Comparing Sentinel-2 MSI and Landsat 8 OLI Imagery for Monitoring Selective Logging in the Brazilian Amazon. Remote Sensing, 11 (8): 961. https://doi.org/10.3390/rs11080961

Longaretti P.-Y., Vannier C., Lasseur R., Lavorel S., 2016. La modélisation des changements d'usage et de couverture des sols comme outil d'aide à la planification territoriale. Sciences Eaux \& Territoires, INRAE, $21:$ 52-57. https://hal.inria.fr/hal-01685718

Ministère des Eaux et Forêts, 2019. Stratégie nationale de préservation, de réhabilitation et d'extension des forêts. Abidjan, $68 \mathrm{p}$. 
Mitchard E., Saatchi S., Lewis S., Feldpausch T., Woodhouse I., Sonké B., et al., 2011. Measuring biomass changes due to woody encroachment and deforestation/degradation in a forest-savanna boundary region of central Africa using multi-temporal L-band radar backscatter. Remote Sensing of Environment, 115 (11): 2861-2873. https://doi.org/10.1016/i.rse.2010.02.022

Mutanga O., Adam E., Cho M. A., 2012. High-density biomass estimation for wetland vegetation using WorldView-2 imagery and random forest regression algorithm. International Journal of Applied Earth Observation and Geoinformation, 18: 399-406. https://doi. org/10.1016/j.jag.2012.03.012

Nakouma S., Beltrando G., Atta K. L., Dibi N’Da H., Brou T., 2013. Dynamique forestière et pression urbaine dans le parc national du Banco (Abidjan, Côte d'Ivoire). VertigO, 13 (2). https://doi. org/10.4000/vertigo.14127

Niculescu Sr. S., Billey A., Talab-Ou-Ali Jr. H., 2018. Random forest classification using Sentinel-1 and Sentinel-2 series for vegetation monitoring in the Pays de Brest (France). Proc. SPIE 10783, Remote Sensing for Agriculture, Ecosystems, and Hydrology XX, 1078305. https://doi.org/10.1117/12.2325546

Olofsson P., Foody M. G., Herold M., Stehman V. S., Woodcock E. C., Wulder A. M., 2014. Good practices for estimating area and assessing accuracy of land change. Remote Sensing of Environnement, 148: 42-57. https://doi.org/10.1016/i.rse.2014.02.015

Oszwald J., Kouakou Atta J.-M., Kergomard C., Robin M., 2007. Représenter l'espace pour structurer le temps: approche des dynamiques de changements forestiers dans le sud-est de la Côte d'Ivoire par télédétection. Télédétection, 7 (1-2-3-4) : 271-282. https://dumas. ccsd.cnrs.fr/LETG-COSTEL/halshs-00437064v1

Ousmane S., Dibi N’Da H., Kouassi K. H., Kouassi K. E., Ouattara K., 2020. Crise politico-militaire et dynamique de la végétation du Parc national du Mont Péko en Côte d'Ivoire. Bois et Forêts des Tropiques, 343 : 27-37. https://doi.org/10.19182/bft2020.343.a31837

Pelletier C., Valero S., Inglada J., Champion N., Dedieu G., 2016. Assessing the robustness of Random Forests to map land cover with high-resolution satellite image time series over large areas. Remote Sensing of Environment, 187: 156-168. https://doi.org/10.1016/j. rse.2016.10.010

Phiri D., Simwanda M., Salekin S., Nyirenda V. R., Murayama Y., Ranagalage M., 2020. Sentinel-2 Data for Land Cover/Use Mapping: A Review. Remote Sensing, 12 (14): 2291. https://doi.org/10.3390/ rs12142291

Pimple U., Simonetti D., Sitthi A., Pungkul S., Leadprathom K., Skupek H., et al., 2018. Google Earth Engine based three decadal Landsat imagery analysis for mapping of mangrove forests and its surroundings in the Trat province of Thailand. Journal of Computer and Communication, 6: 247-264. https://doi.org/10.4236/ jcc.2018.61025

Pontius Jr. R. G., 2000. Quantification error versus location error in comparison of categorical maps. Photogrammetric Engineering and Remote Sensing, 66 (8): 1011-1016.

Puyravaud J.-P., 2002. Standardizing the calculation of the annual rate of deforestation. Forest Ecology and Management, 177 (1-3): 593-596. https://doi.org/10.1016/S0378-1127(02)00335-3

Rakotomala F. A., Rabenandrasana J. C., Andriambahiny J. E., Rajaonson R., Andriamalala F., Buren C., et al., 2015. Estimation de la déforestation des forêts humides à Madagascar utilisant une classification multidate d'images Landsat entre 2005, 2010 et 2013. Revue Française de Photogrammétrie et de Télédétection, 211-212.

Rodriguez-Galiano V. F., Ghimire B., Rogan J., Chica-Olmo M., Rigol-Sanchez J. P., 2012. An assessment of the effectiveness of a random forest classifier for land-cover classification. ISPRS Journal of Photogrammetry and Remote Sensing, 67: 93-104. https://doi. org/10.1016/j.isprsjprs.2011.11.002

Ruf F., 2012. L'adoption de l'hévéa en Côte d'Ivoire. Prix, mimétisme, changement écologique et social. Économie Rurale, 330331. https://doi.org/10.4000/economierurale.3527

Semeki Ngabinzeke N., Linchant J., Quevauvillers S., Kahindo M. J.-P., Lejeune P., Vermeulen C., 2016. Potentiel des véhicules aériens sans pilote dans la détection des activités humaines illégales dans les aires protégées en République Démocratique du Congo. Journal of Unmanned Vehicle Systems, 4 (2): 151-159. https://doi. org/10.1139/iuvs-2015-0035

Semeki Ngabinzeke J., Pitchugin M., Linchant J., Vermeulen C., Kahindo Muhongya J.-M., Lejeune P., 2018. Une méthode simple et rapide pour l'évaluation de statistiques d'occupation du sol à l'aide d'images à très haute résolution acquises par mini-drone. Bois et Forêts des Tropiques, 335 : 15-23. https://doi.org/10.19182/ $\underline{\text { bft2018.335.a31497 }}$
SEP-REDD+. 2017. Niveau d'émissions de référence pour les forêts de la Côte d'Ivoire. Présentation à la Convention-cadre des Nations unies sur les changements climatiques. République de Côte d'Ivoire, 43 p. https://redd.unfccc.int/files/rci_nrf_ccnucc_2017.10.15.pdf Thiérion V., Herrault P. A., Vincent A., Inglada J., Sheeren D., 2017. Utilisation des séries temporelles d'images Sentinel-2 pour la cartographie de l'occupation du sol dans un contexte de modélisation de la biodiversité. Colloque PAYOTTE 2017, Paris, France. https://hal. inrae.fr/hal-02738272

Vaudry R., Nourtier M., Bello A., Traoré Y., 2016. Analyse qualitative des facteurs de la déforestation et de la dégradation des forêts en Côte d'Ivoire. Rapport final. Association Etc Terra, 114 p.

Verrelst J., Rivera J. P., Veroustraete F., Muñoz-Marí J., Clevers J. G. P. W., Camps-Valls G., et al., 2015. Experimental Sentinel-2 LAI estimation using parametric, non-parametric and physical retrieval methods - A comparison. ISPRS Journal of Photogrammetry and Remote Sensing, 108: 260-272. https://doi.org/10.1016/j. isprsjprs.2015.04.013

Vuolo F., Atzberger C., 2014. Improving Land Cover Maps in Areas of Disagreement of Existing Products using NDVI Time Series of MODIS - Example for Europe. Photogrammetrie - Fernerkundung - Geoinformation, 2014 (5): 393-407. https://doi. org/10.1127/1432-8364/2014/0232

WCF, 2020. Cocoa and Forests initiative. Private Sector Report 20182019. Washington, DC, USA, World Cocoa Foundation, 53 p.

\begin{tabular}{|c|c|}
\hline \multicolumn{2}{|c|}{ Ouattara et al. - Contribution des auteurs } \\
\hline Rôle du contributeur & Noms des auteurs \\
\hline Conceptualisation & $\begin{array}{l}\text { T. A. Ouattara, K. F. Kouamé, } \\
\text { C. Grinand, R. Vaudry }\end{array}$ \\
\hline Gestion des données & T. A. Ouattara \\
\hline Analyse formelle & T. A. Ouattara, C. Grinand \\
\hline $\begin{array}{l}\text { Acquisition } \\
\text { du financement }\end{array}$ & $\begin{array}{l}\text { T. A. Ouattara, K. F. Kouamé, } \\
\text { I. C. Zo-Bi, C. Grinand, R. Vaudry }\end{array}$ \\
\hline $\begin{array}{l}\text { Enquête } \\
\text { et investigation }\end{array}$ & $\begin{array}{l}\text { T. A. Ouattara, C. Grinand, } \\
\text { R. Vaudry }\end{array}$ \\
\hline Méthodologie & $\begin{array}{l}\text { T. A. Ouattara, K. F. Kouamé, } \\
\text { C. Grinand, I. C. Zo-Bi }\end{array}$ \\
\hline Gestion de projet & T. A. Ouattara, C. Grinand, R. Vaudry \\
\hline Ressources & T. A. Ouattara, R. Vaudry \\
\hline Logiciels & T. A. Ouattara, C. Grinand \\
\hline Supervision & $\begin{array}{l}\text { K. F. Kouamé, I. C. Zo-Bi, } \\
\text { C. Grinand, R. Vaudry }\end{array}$ \\
\hline Validation & K. F. Kouamé, I. C. Zo-Bi, C. Grinand \\
\hline Visualisation & $\begin{array}{l}\text { T. A. Ouattara, K. F. Kouamé, } \\
\text { I. C. Zo-Bi, C. Grinand, R. Vaudry }\end{array}$ \\
\hline $\begin{array}{l}\text { Écriture - Préparation } \\
\text { de l'ébauche originale }\end{array}$ & $\begin{array}{l}\text { T. A. Ouattara, K. F. Kouamé, } \\
\text { I. C. Zo-Bi, C. Grinand, R. Vaudry }\end{array}$ \\
\hline $\begin{array}{l}\text { Écriture - Révision } \\
\text { et édition }\end{array}$ & $\begin{array}{l}\text { T. A. Ouattara, K. F. Kouamé, } \\
\text { I. C. Zo-Bi, C. Grinand, R. Vaudry }\end{array}$ \\
\hline
\end{tabular}

Bois et Forêts des Tropiques - Revue scientifique du Cirad (c) Bois et Forêts des Tropiques (c) Cirad
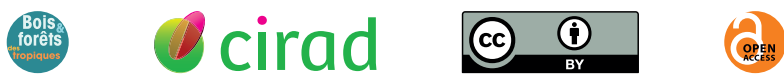

Cirad - Campus international de Baillarguet, 34398 Montpellier Cedex 5, France - Contact : bft@cirad.fr - ISSN : L-0006-579X 